\title{
EL SISTEMA INTERAMERICANO DE DERECHOS HUMANOS Y LAS RELACIONES ESTADOS UNIDOS-AMÉRICA LATINA
}

Par Engstrom

El Sistema Interamericano de Derechos Humanos (Sidh) ha sido parte integral del paisaje institucional regional de América Latina desde mediados del siglo xx. El sistema regional de derechos humanos se ha desarrollado en las condiciones específicas que prevalecen en la región. Un desarrollo progresivo de la jurisprudencia de los derechos humanos regionales se refleja en la forma como el sistema se esforzó, conforme crecía, durante la primera etapa de la Guerra Fría, para promover los derechos humanos en la región, así como en su manera de juzgar los cálculos políticos de los gobiernos de transición. Dichos procesos recibieron nuevo empuje con la vuelta al orden democrático en la región; en este sentido, la dirección del Sistema Interamericano como un todo quedó ligada al mantenimiento y progreso de la democracia política. Desde luego, con todo, el régimen democrático como tal no es garantía de respeto de los derechos humanos, pues el sistema ha volcado su atención al reto de asegurar la calidad del orden democrático. El sistema ha establecido la obligación legal conforme a jurisprudencia regional e internacional de los Estados para proteger los derechos de los ciudadanos y, de fallar en hacerlo, la obligación internacional de que los Estados respondan. El Sistema Interamericano de Derechos Humanos, de esa manera, se ha ido convirtiendo en un régimen transnacionalizado conforme se ha abierto a la actividad política transnacional. ${ }^{1}$

\footnotetext{
${ }^{1}$ Reconocimientos: el autor agradece los comentarios de dos dictaminadores
} 
Con todo, el desarrollo institucional del sidH debe entenderse en un contexto histórico y geopolítico más amplio de las relaciones Estados Unidos-América Latina, lo que define aún más el funcionamiento del sistema. Muchos consideran el SIDH como una extensión de la política exterior estadounidense; argumentan que mientras que los medios de la política exterior estadounidense pueden haber cambiado a lo largo de los años, la presunción hegemónica de quienes formulan la política de Estados Unidos esencialmente perdura. Otros señalan la continuidad de la ideología expansionista estadounidense, encarnada históricamente en la idea del "destino manifiesto", que justifica las políticas intervencionistas en América Latina. Estas percepciones son duraderas y prosiguen moldeando la legitimidad y la efectividad del SIDH, según se observa en las controversias sobre el historial de derechos humanos en Venezuela en años recientes.

De cualquier forma, el SIDH nunca ha sido un instrumento de política exterior inequívoco para Estados Unidos. En primer lugar, esto restaría importancia al papel que los juristas y diplomáticos latinoamericanos jugaron en los comienzos del desarrollo del régimen internacional de derechos humanos, tanto en las Naciones Unidas como regionalmente en América Latina. Desde su insistencia en una gama completa de derechos, incluidos los socioeconómicos, a su cabildeo para que las instituciones de derechos humanos intervengan en asuntos internos de los Estados, las posiciones de los representantes de los gobiernos latinoamericanos no han reflejado necesariamente las preferencias normativas de Estados Unidos. En segundo lugar, crucialmente, el sIDH se ha desarrollado a lo largo de los años desde un régimen intergubernamental "clásico" a un espacio político transnacional con un orden de gran alcance para regular las normas de política

anónimos a un borrador de este artículo. Una versión de este material aparecerá en Juan Pablo Scarfi y Andrew Tillman (eds.), Cooperation and Hegemony in U.S.-Latin American Relations, Palgrave Macmillan (2015). Se reproduce aquí con aprobación de Palgrave Macmillan. Para más detalle, véase: Par Engstrom, "Transnational Human Rights and Democratization: Argentina and the Inter-American Human Rights System (1976-2007)”, tesis doctoral, University of Oxford, 2010, caps. 1-2. 
interna y las prácticas de Estados en la región. El sistema aflora, desde sus raíces como entidad regida por el gobierno con un mandato impreciso para promover el respeto por los derechos humanos en la región, como un régimen legal que fortalece a los ciudadanos para que desafíen las actividades internas de sus propios gobiernos. Se confiere a una corte y a una comisión independientes el mandato para responder a demandas individuales por la determinación de si la aplicación de normas internas o legislaciones violan los compromisos internacionales. El acceso de los particulares al régimen de derechos humanos se ha ido fortaleciendo, mientras que el sistema se ha convertido en un régimen judicial con un enfoque procesal en la fuerza de los argumentos legales y la generación de jurisprudencia de los derechos humanos regionales. La erosión gradual del control del Estado en general, y la influencia de Estados Unidos en particular, sobre el sIDH ha sido claramente irregular, como demuestra la constante dependencia del SIDH en la financiación estadounidense. Aún así, han sucedido cambios fundamentales en las últimas décadas en particular, a la vez que los actores de los derechos humanos latinoamericanos, gubernamentales o no, han tenido parte en estos cambios institucionales.

No obstante, muchos de los desafíos del sidH permanecen engastados en las tendencias cambiantes de las relaciones entre Estados Unidos y América Latina. Ciertamente, el sidH no está separado de la relación plena entre Estados Unidos y América Latina. Este artículo busca esclarecer esta relación en tres partes principales. La primera parte del artículo destaca cuatro aspectos clave de las relaciones entre los Estados, las cuales continúan definiendo los desarrollos institucionales: $i$ ) un proceso, basado tradicionalmente en el Estado y dirigido por una élite, de institucionalización regional sobre la base de objetivos prominentes; ii) la combinación de interdependencia e inequidad que caracteriza a la relación entre Estados Unidos y América Latina y el Caribe; iii) continuas tensiones entre los principios de soberanía y normas y prácticas de intervención; y iv) las brechas polifacéticas entre la promoción de los derechos humanos en el exterior y un historial de derechos humanos asaz problemático en el interior, por una parte, y, por la otra, el compromiso declarado de 
plantear principios de derechos humanos en papel y violarlos en casa. La segunda parte rastrea los cambios y continuidades en las dinámicas interestatales que han definido la operación del sidH y su capacidad de provocar un cambio en los derechos humanos desde la Guerra Fría hasta el periodo de rejuvenecimiento institucional de la década de 1990. La última parte señala algunos de los muchos desafíos que enfrenta el sidH y la manera como el carácter de las relaciones entre Estados Unidos y América Latina sigue moldeando la capacidad del sistema para atender estos retos.

\section{Características institucionales del Sistema Interamericano de Derechos Humanos}

Los intentos por organizar los Estados en la región en un cuerpo cooperativo internacional tienen sus orígenes en la era de las independencias nacionales en la primera parte del siglo xıx. ${ }^{2}$ La adopción de la fundacional Carta de la Organización de los Estados Americanos (OEA) en 1948 debería entonces verse a la luz de más de un siglo de relaciones interamericanas que determinaron las normas y principios adoptados en la Carta de la oeA. Desde su creación, la oEA ha venido a encapsular en sentido general el sistema regional de cooperación interestatal en el que el régimen interamericano de derechos humanos queda inscrito.

Esta sección considera el contexto institucional en que las normas regionales y prácticas concernientes a los derechos humanos se han desarrollado; examina cómo este desarrollo se ha formado por el carácter de las relaciones Estados Unidos-América Latina y destaca cuatro dimensiones clave del sistema regional de derechos humanos, según queda asentado en la Carta de la oeA y en acuerdos ulteriores de derechos humanos.

${ }^{2}$ Louise Fawcett, "The Origins and Development of Regional Ideas in the Americas”, en Louise Fawcett y Mónica Serrano (eds.), Regionalism and Governance in the Americas: Continental Drift, Basingstoke, Palgrave Macmillan, 2005. 


\section{Ambiciones normativas}

Desde el temprano periodo de las independencias de las repúblicas latinoamericanas, los gobiernos aspiraron a un sistema regional de cooperación basado en objetivos ambiciosos. Los diplomáticos latinoamericanos y las élites políticas han hecho repetidos llamados a la solidaridad regional, basándose en cultura y valores compartidos. Simón Bolívar convocó en 1826 a una confederación regional de Estados para defender la democracia, ${ }^{3} \mathrm{y}$ ha habido invocaciones frecuentes a que la identidad de América Latina debiera apoyar la cooperación institucional entre las repúblicas independientes de la región. Seis Conferencias Panamericanas, llevadas a cabo de 1889 a 1928, marcaron el desarrollo de un marco institucional primigenio para las relaciones interamericanas que buscaban colocar un marco estable para la gestión de las relaciones regionales.

Es importante notar que mucho de este proceso inicial de institucionalización regional fue llevado por diplomáticos latinoamericanos y abogados internacionales. La Séptima Conferencia en 1933 adoptó una convención sobre los derechos y obligaciones de los Estados, la cual formulaba el principio de no intervención en los asuntos internos de los Estados, y en la Octava Conferencia en 1938 se adoptaron resoluciones que llamaban a la defensa de los derechos humanos. Se abordó este tema en la Conferencia Interamericana sobre Problemas de la Guerra y de la Paz en 1945, cuando se requirió al Comité Jurídico Interamericano a redactar una declaración sobre la protección de los derechos humanos. ${ }^{4}$ De aquí que antes de la adopción de la Carta de la oeA en 1948 existiese una aceptación sólida y extendida de los principios de los derechos humanos en la región. En particular, como aclara

${ }^{3}$ David Forsythe, "Human Rights, The United States and the Organization of American States", Human Rights Quarterly, vol. 13, pp. 75-76.

${ }^{4}$ La Conferencia también discutió la "Propuesta Larreta", tomada del ministro uruguayo de Relaciones Exteriores Eduardo Rodríguez Larreta, que proponía a los gobiernos americanos suspender o restringir el principio de no intervención en los asuntos internos de otro país, y llamó a una acción multilateral para defender la democracia y los derechos humanos. La propuesta nunca se aprobó formalmente. 
Forsythe, "un número pequeño de Estados latinoamericanos en la década de 1940 intentó ejercer liderazgo moral como apoyo a obligaciones legales precisas y a una capacidad para la acción regional sobre los derechos humanos. Este puñado de Estados latinoamericanos -Panamá, Uruguay, Brasil, México, República Dominicana, Cuba y Venezuela- también presionó para asegurar compromisos de derechos humanos en la conferencia de San Francisco, que llevó a la fundación de las Naciones Unidas". ${ }^{5}$ De hecho, en la conferencia de San Francisco, que adoptó la Declaración de Derechos Humanos, al igual que en la oEA, diplomáticos latinoamericanos y juristas internacionales jugaron papeles prominentes para impulsar ambiciosas resoluciones sobre derechos humanos. ${ }^{6}$ Estas aspiraciones normativas reflejaron procesos nacionales a través de los cuales las repúblicas independientes a lo largo de la región habían adoptado constituciones liberales que incorporaban una gama ambiciosa de principios y protecciones de derechos humanos. ${ }^{7}$

\section{Interdependencia e inequidad}

El segundo aspecto por señalarse concierne a la particular combinación de interdependencia e inequidad que ha caracterizado históricamente las relaciones interestatales regionales. Los ambiciosos cambios institucionales ocurrieron en un contexto de asimetrías del poder duro y ante unos Estados Unidos cada vez más poderosos y expansionistas. Por una parte, el ascenso de Estados Unidos tuvo el efecto de que la idea de una cooperación más cercana entre Estados latinoamericanos independientes que se basaba en rasgos en común saliera perdiendo ante el orden regional dirigido por Estados Unidos, que se formalizó con la creación de la oEA en

${ }^{5}$ David Forsythe, art. cit.

${ }^{6}$ Mary Ann Glendon, "The Forgotten Crucible: The Latin American Influence on the Universal Rights Idea”, Harvard Human Rights Journal, vol. 16, 2003.

7 Paolo G. Carozza, "From Conquest to Constitutions: Retrieving a Latin American Tradition of the Idea of Human Rights", Human Rights Quarterly, vol. 25, núm. 2, 2003, pp. 281-313. 
1948. ${ }^{8}$ Por otra parte, la fuerte disparidad de poder combinada con intervenciones periódicas llevó a esfuerzos para establecer dispositivos contra la intervención estadounidense. Como señala $\mathrm{Hu}$ rrel: "más allá de la política propiamente elegida, su sola presencia y la posibilidad de maniobra de Estados Unidos han sido siempre factores en las mentes de los gobiernos latinoamericanos. Está en la naturaleza de la hegemonía que las acciones y reacciones sean influidas por las expectativas de lo que Estados Unidos haga o deje de hacer" ${ }^{9}$ En otras palabras, la oeA institucionalizó el principio de no intervención como salvaguarda legal contra la hegemonía estadounidense.

Y aún así, la cercanía de los Estados latinoamericanos con Estados Unidos, particularmente de Centroamérica y el Caribe, en combinación con la interdependencia material regional y disparidades dramáticas de riqueza, han llevado a peticiones frecuentes y demandas de alto nivel en Estados Unidos para jugar un papel más activo en proveer bienes colectivos. Más allá del marco de seguridad de Estados Unidos de rechazo estratégico de las potencias extrarregionales, quienes formulan las políticas en ese país han solido contemplar sólo medidas limitadas de apoyo para el desarrollo (p. e., la Alianza para el Progreso) y casi ninguna ayuda similar a la enviada a otras regiones, como a Europa tras la Segunda Guerra Mundial. Esta combinación de inequidad e interdependencia ha ocasionado profunda ambivalencia de parte de las élites latinoamericanas respecto del papel de Estados Unidos. ${ }^{10}$ También ha conformado hondas corrientes de pensamiento político en América Latina que contemplan las iniciativas de Estados Unidos hacia la región como irremediablemente imperialistas. Es justamente esta combinación de interdependencia e inequidad la que hace a los arreglos políticos regionales tan difíciles de gestionar. ${ }^{11}$

${ }^{8}$ En los últimos años, para efectos de entender el orden regional, han reaparecido tensiones entre ideas de "panamericanismo" y "bolivarianismo".

9 Andrew Hurrell, "Security in Latin America", International Affairs, vol. 74, núm. 3, 1998, p. 531.

${ }^{10}$ Robert A. Pastor, Exiting the Whirlpool: U.S. Foreign Policy Toward Latin America and the Caribbean, Boulder, Westview, 2001.

${ }^{11}$ Andrew Hurrell, "Security in Latin America", p. 546. 


\section{Soberanía e intervención}

Una tercera dimensión atañe a las tensiones normativas e institucionales entre la soberanía de los Estados y el ámbito de intervención legítima en los asuntos internos de los Estados. Dadas las circunstancias históricas de la disparidad de poder regional en que se formaron los Estados americanos, ciertos principios -sobre todo la autodeterminación, el derecho a la independencia y la libertad de no recibir intervención- vinieron a guiar las tentativas de cooperación regional. De cualquier forma, estas normas se han desarrollado a la par de aquellas de la democracia y los derechos humanos, con inevitables tensiones institucionales. Los representantes estatales en la Conferencia de Bogotá en 1948 instituyeron normas de derechos humanos por medio de varias resoluciones entre las que destacan la Carta original de la oEA y la Declaración Americana de los Derechos y Deberes del Hombre. Con todo, en la misma Conferencia se adoptó también una resolución sobre la "Preservación y Defensa de la Democracia en América”, y los gobiernos signatarios de la resolución acordaron tomar cualesquier medidas necesarias para asegurar que no se violaría "el derecho libre y soberano de los pueblos a gobernarse de acuerdo a sus propias aspiraciones".

Sin duda, no preocupaba sólo a países latinoamericanos más débiles la intervención externa en sus asuntos internos. Aunque Estados Unidos respaldaba en principio los derechos humanos, no aceptaba obligación legal alguna que legitimase acciones para hacer cumplir estos principios. Como documentó Forsythe, "en 1948, sólo seis de veintiún Estados, que no incluían a Estados Unidos, querían que la Declaración Americana de los Derechos y Deberes del Hombre formara parte de la Carta de la oEA, conque se vinculara al derecho internacional. Y sólo ocho de veinte Estados electores, de nuevo sin Estados Unidos, deseaban una convención vinculante sobre derechos humanos". ${ }^{12}$ Debe notarse, con todo, que los representantes de los gobiernos latinoamericanos ocasionalmente estaban dispuestos a promover la intervención, como se ha visto, por

\footnotetext{
${ }^{12}$ David Forsythe, art. cit.
} 
ejemplo, en los esfuerzos de Uruguay en 1946 para promover la "Doctrina Larreta", que llamaba a la intervención en Argentina.

\section{El derecho y el hecho}

El último aspecto por notar concierne a la brecha entre la retórica y la práctica. El apoyo a la democracia y a los derechos humanos ha sobresalido históricamente en la agenda regional, bien que, al inicio, sólo de manera retórica. También en el plano declaratorio, las instituciones regionales se han sustentado con la idea de que el reconocimiento universal de los derechos fundamentales es una condición necesaria para la vida internacional y el asentamiento de sociedades democráticas. Hay dos dimensiones en la brecha entre la adhesión verbal a los principios de los derechos humanos en los Estados y el compromiso de los Estados miembros de llevar estos ideales a la práctica.

Hay en primer lugar la brecha entre los principios abstractos aceptados en el discurso, por una parte, y los mecanismos reales dispuestos para asegurar el cumplimiento de estos principios. Con la creación de la oea se adoptó una Declaración Americana de los Derechos y Deberes del Hombre (la declaración), que precedió a la Declaración Universal de Derechos Humanos (DUDH). Este repertorio de derechos tomó la forma de una declaración con la intención de impulsar más adelante un tratado multilateral, ${ }^{13}$ si bien, claramente, la declaración no suponía ser vinculante en los Estados signatarios. ${ }^{14}$ En segundo lugar, hay también una brecha entre principios apoyados diplomáticamente en foros internacionales y la renuencia, en el mejor de los casos, para garantizar la implementación interna de estos principios. A lo largo de su existencia, la oeA -de la que el régimen internacional de derechos

${ }^{13}$ David J. Padilla, "The Inter-American System for the Promotion and Protection of Human Rights", Georgia Journal of International and Comparative Law, vol. 20, núm. 2, 1990, p. 396.

14 Thomas Buergenthal y Dinah Shelton, Protecting Human Rights in the Americas: Cases and Materials, Estrasburgo, International Institute of Human Rights, 1995, p. 39. 
humanos deriva su autoridad-se ha compuesto de Estados miembros entre los que muchos en ocasiones numerosas han sido gobernados por regímenes represivos con consideración escasa de los derechos humanos. Como anota Farer, en comparación con el régimen de derechos humanos europeo, el sidH ha tenido un mandato más amplio que su contraparte de ultramar; pero, mientras que el régimen europeo de derechos humanos "reafirmaba ampliamente las restricciones nacionales sobre el ejercicio del poder ejecutivo y legislativo", el régimen "latinoamericano" "intentaba imponer restricciones a los gobiernos sin paralelo interno". ${ }^{15}$ Más aún, estas características tienen profundas raíces históricas, pues "al ser los hijos de las revoluciones francesa y estadounidense, las élites políticas latinoamericanas hablaban el lenguaje de los derechos desde sus primeras pugnas por la independencia". ${ }^{16}$ Éste es un discurso que no ha evitado el rechazo estructural de aquellos derechos de parte de las élites gobernantes por toda la región. ${ }^{17}$

\section{Cambios y continuidades en el Desarrollo del Sistema InTERAMERICANO De Derechos Humanos}

Esta sección esboza el desarrollo del siDH desde sus orígenes, como un sistema fundamentado en el Estado inscrito profundamente en las dinámicas políticas de las relaciones interestatales durante la Guerra Fría, hasta el sistema transnacional surgido en décadas recientes. Se examina adelante cómo los cambios y las continuidades en las relaciones entre Estados Unidos y América Latina han definido la operación del sistema y su capacidad de influir en las políticas de los derechos humanos.

15 Tom Farer, "The Rise of the Inter-American Human Rights Regime: No Longer a Unicorn, Not Yet an Ox”, Human Rights Quarterly, vol. 19, núm. 3, 1997, pp. 511-512.

${ }^{16}$ Francisco Panizza, "Human Rights: Global Culture and Social Fragmentation”, Bulletin of Latin American Research, vol. 12, núm. 2, 1993, p. 206.

17 Claramente, estas discrepancias entre retórica y práctica no son únicas en países latinoamericanos. Véase Michael Ignatieff (ed.), American Exceptionalism and Human Rights, Princeton, Princeton University Press, 2005. 


\section{El SIDH y la Guerra Fría}

Desde la adopción de la Doctrina Monroe, la política estadounidense hacia su región buscó apartar a las potencias extrahemisféricas. Después de 1948, esto se reformuló dentro de una lógica de la Guerra Fría que se basaba en el rechazo estratégico de ventaja a la Unión Soviética. Luego de la aprobación de de la Carta de la oeA y de la Declaración Americana de los Derechos y Deberes del Hombre, la Guerra Fría vino a determinar el sidH durante las primeras cuatro décadas de su existencia.

De hecho, el sidH jugó ocasionalmente un papel provechoso a la política exterior de los Estados. En particular, en los primeros tiempos el sidH gozaba de un contexto permisivo para un sistema regional de derechos humanos impulsado por los Estados. Preocupaba a Estados Unidos mantener a gobiernos de izquierda fuera de América Latina y expulsar a aquellos que emergieran. En las tensiones que llevaron al derrocamiento respaldado por Estados Unidos del régimen de Arbenz en Guatemala en junio de 1954, la conferencia de los Estados miembros de la oeA celebrada en Caracas afirmó la relación necesaria entre un sistema basado en la democracia y la protección de los derechos humanos. ${ }^{18}$ La Conferencia adoptó una declaración que manifestaba la solidaridad de los Estados del hemisferio contra "la intervención del comunismo internacional”. La declaración se aprobó con la insistencia de Estados Unidos, contra la discrepancia de Argentina, México (ambos se abstuvieron) y Guatemala (que votó en contra). ${ }^{19}$

Era, en parte, una respuesta al régimen de Trujillo en República Dominicana, y particularmente a la fuerza creciente de la Revolución cubana, por lo que la política latinoamericana de Estados Unidos se endureció. Esto tuvo consecuencias para el sidH. Ante un ambiente político donde el gobierno venezolano se preocupaba sobre los intentos del gobierno de Trujillo para causar

18 La Conferencia celebrada en marzo de 1954 adoptó la Declaración de Caracas, que sostenía que un medio efectivo para fortalecer las instituciones democráticas es el respeto a los derechos humanos sin discriminación alguna.

19 Disponible en http://avalon.law.yale.edu/20th_century/intam10.asp Se consultó el 3 de octubre de 2013. 
inquietud en Venezuela, y ante la creciente preocupación del gobierno de Eisenhower sobre los eventos en Cuba, la oEA acordó un compromiso para comprometerse a establecer una comisión para la protección de los derechos humanos. ${ }^{20}$ La consiguiente declaración de Santiago llamó, entre otras cosas, a la creación de una Comisión Interamericana de Derechos Humanos, y afirmó que la falta de respeto a los derechos humanos y a la democracia habían sido una causa mayor de inquietud en la región, y que los regímenes antidemocráticos estaban en desacato de la Carta de la OEA, conque se arriesgaban las relaciones pacíficas en la región. ${ }^{21}$ Como resultado, se creó la CIDH en 1959 con la consigna de emplear estándares de la Declaración para evaluar la conducta de los Estados en asuntos de derechos humanos. ${ }^{22}$ De cualquier manera, desde su origen, la Comisión hubo de operar en un ambiente regional donde se prestaba escasa atención a los derechos humanos. En otras palabras, se estableció la Comisión dentro del marco de la oEA

${ }^{20}$ David Forsythe, art. cit., pp. 82-83. Forsythe documenta la reticencia de muchos miembros de la oEA para autorizar la creación de un órgano intrusivo de derechos humanos, en combinación con el interés estadounidense en una institución política maleable para ganar influencia contra los liderazgos de Cuba y Venezuela. "Se alcanzó un compromiso político, que admitía las demandas de Venezuela sobre la República Dominicana y la preocupación de Estados Unidos por Cuba, a la vez que aseguraba que la oEA no sobrepasaba demasiado las murallas de la soberanía nacional”.

${ }^{21}$ La Quinta Reunión de Consulta de Ministros de Relaciones Exteriores en agosto de 1959 llamó a la creación de una Convención y Comisión para la protección de los derechos humanos, y adoptó la Declaración de Santiago. La Declaración postula que la armonía entre las repúblicas americanas sólo puede ser efectiva mientras que los derechos humanos y las libertades fundamentales sean una realidad [...]".

${ }^{22}$ La Comisión serviría para cumplir lo que la Carta afirmaba como su función principal: "promover el cumplimiento y la protección de los derechos humanos y funcionar como órgano consultivo de la Organización para estos asuntos”. Artículo 111 de la Carta original (el 106 de la Carta enmendada por el Protocolo de la Carta enmendada según el Protocolo de Managua en 1993), que entró en vigor en 1996. Cecilia Medina observa que la Comisión estaba "originalmente concebida como un grupo de estudio con investigaciones abstractas en el campo de los derechos humanos". Cecilia Medina, "Inter-American Commission on Human Rights and the Inter-American Court of Human Rights: Reflections on a Joint Venture", Human Rights Quarterly, vol. 12, núm. 4, 1990, p. 440. 
para promover los derechos humanos antes de que el respeto a los derechos se convirtiera en una obligación legal clara y precisa, es decir, construida para promover pero no dar la autoridad o los procedimientos para proteger ${ }^{23}$ La Comisión, como contempló la mayoría de los Estados miembros de la oEA, se dedicó a hacer estudios generales y a promover la educación sobre los derechos humanos. Estados Unidos, cuya preocupación mayor se centraba en las presiones diplomáticas sobre República Dominicana y, particularmente, Cuba, se abstuvo en el voto que creaba la Comisión. Ésta surgía, en otras palabras, del compromiso en respuesta a las demandas de Venezuela sobre el régimen de Trujillo, por un lado, y de la preocupación estadounidense sobre Cuba, por el otro, mientras que se aseguraba de que se atendieran las preocupaciones de otros Estados sobre una Comisión de derechos humanos demasiado intrusiva. ${ }^{24}$ Con ello, la atención inicial y la labor de la Comisión en Cuba y República Dominicana permitieron la aprobación de la administración de Eisenhower; ${ }^{25}$ también facilitaron a los miembros de la Comisión un contexto para consolidar las prácticas institucionales de la Comisión.

Durante la administración de Kennedy, la oEA recibió cierto apoyo para las acciones para derechos humanos. Con la iniciativa emblemática de la administración de Kennedy para Latinoamérica, la Alianza para el Progreso, Estados Unidos buscó "revolucionar la contrarrevolución”. Los objetivos primordiales eran evitar el comunismo (con apoyo militar y entrenamiento en técnicas antiinsurgentes) y promover la democracia, que se creía en los años sesenta que dependía de la mitigación de la pobreza (por efecto de un paquete de reformas modernizadoras, incluida la de la tierra). Entre 1961 y 1963, Estados Unidos suspendió o rompió relaciones diplomáticas con varios países con dictaduras, entre ellos Argentina, República Dominicana, Ecuador, Guatemala, Honduras y Perú. Pero estas suspensiones se impusieron sólo temporalmente, por

${ }^{23}$ Carlos García Bauer, "The Observance of Human Rights and the Structure for their Protection in the Western Hemisphere", American University Law Review, vol. 30, núm. 14, 1980-1981, p. 15.

${ }^{24}$ David Forsythe, art. cit., pp. 82-83.

${ }^{25}$ Ibid., p. 84. 
periodos de apenas tres semanas y hasta seis meses. Más aún, el impulso reformador de Estados Unidos durante la administración de Kennedy, en sus términos, fue tan ineficaz como efímero. Durante la década de 1960, trece gobiernos constitucionales de América Latina se reemplazaron con dictaduras militares. Y en marzo de 1964, en tiempo del presidente Johnson, Estados Unidos aprobó un golpe militar en Brasil, y se preparó para intervenir más activamente de ser necesario con la Operación Brother Sam. Además, en 1965 Estados Unidos despachó 24000 efectivos a República Dominicana como respuesta a la agitación política y para evitar lo que la administración de Johnson consideraba como una "segunda Cuba" en potencia.

En breve, el desarrollo institucional del SIDH en sus primeros años se modeló fundamentalmente por el carácter de las relaciones entre Estados Unidos y América Latina, según lo figuró la Guerra Fría. Es importante con todo insistir en esta coyuntura, de la que, de manera intermitente, otros Estados, además de Estados Unidos, se han servido para canalizar sus políticas exteriores en el SIDH, y a veces incluso para desafiar las políticas estadounidenses. Por ejemplo, en 1977, el general Omar Torrijos sacó ventaja del SIDH para contrarrestar acusaciones de violaciones a los derechos humanos hechas por sus oponentes en el Senado de Estados Unidos que se oponían al tratado que cedía el control del Canal de Panamá. De la misma forma, el gobierno sandinista que siguió a la caída del régimen de Somoza en Nicaragua recurrió al sidH en 1981 para oponerse a las acusaciones estadounidenses de violaciones a los derechos humanos.

De cualquier modo, la lógica de Estado en el sistema limitó su capacidad para provocar un cambio en derechos humanos. Sin duda, la mayoría de los miembros de la oeA -recelosos de las posibilidades de intervención en nombre de la supervisión de los derechos humanos- estaban más tranquilos con un sistema encargado de realizar estudios generales de derechos humanos, que si el mismo se ocupara de situaciones de violación a los derechos humanos. Como revela la respuesta nula de la CIDH a los abusos sistemáticos a los derechos humanos que siguieron al golpe militar en Brasil, el sistema regional de derechos humanos se mantuvo discreto en la 
región. Así lo demostró después por el número reducido de solicitudes a la Comisión de parte de organizaciones de derechos humanos nacientes en la región, aun diez años después de creada la Comisión. ${ }^{26}$

Hubo, sin embargo, acontecimientos en el sidH que fueron significativos, pese a la falta de apoyo de los Estados miembros de la oEA. La competencia de la Comisión se formalizó en 1965 con una resolución de la oEA que autorizaba a la Comisión a "examinar" violaciones aisladas de derechos humanos, con atención especial a ciertos derechos. ${ }^{27} \mathrm{Al}$ hacerlo, las actividades de la Comisión respecto del manejo de las comunicaciones individuales se atribuyeron con base legal. La inserción de un elemento legal en un procedimiento que hasta entonces había sido altamente político introdujo en el Sistema Interamericano la "idea de que los derechos humanos se podrían proteger también por medio de un procedimiento cuasi-judicial". ${ }^{28}$ De aquí que la Comisión asumiera la práctica de elaborar investigaciones detalladas y de dar a conocer violaciones serias, con el fin de presionar a Estados miembros para respetar los derechos humanos asentados en la Declaración. La enmienda de 1967 a la Carta de la oEA mejoró el estatus de la Comisión al destinarla por primera

${ }^{26}$ Tom Farer, "The Rise of the Inter-American Human Rights Regime”, pp. 526-527.

${ }^{27}$ La Resolución de la Asamblea General de la oEA XxiI (1965) encomendó a la Comisión poner especial atención al cumplimiento de los derechos humanos dispuestos en la Declaración Americana de los Derechos y Deberes del Hombre en los artículos I (el derecho a la vida, la libertad y la seguridad personal), II (derecho a la igualdad ante la ley), III (derechos a la libertad de religión y de culto), IV (derecho a la libertad de investigación, opinión, expresión y difusión), XVIII (derecho a un juicio justo), xxv (derecho a la protección contra la detención arbitraria) y xxvi (derecho a un debido proceso). Por consiguiente, la encomienda de la Comisión se restringió a la atención inicial de los derechos políticos y civiles, lo que redujo la misión a proteger los derechos económicos, sociales y culturales. Más aún, se extendió la restricción para que la Comisión tuviera que determinar si las soluciones internas habían sido exhaustivas antes de enviarlas a la Comisión. En fin, la resolución aumentó también la autoridad de la Comisión para buscar información y emitir recomendaciones a los gobiernos miembros.

${ }^{28}$ Medina Quiroga, The Battle of Human Rights, pp. 83-85. 
vez a "proteger" así como a "promover" los derechos humanos. Aún así, ni a la Comisión ni a los derechos que suponía proteger se dio la base legal sólida de un tratado sino hasta la Convención Americana sobre los Derechos Humanos (en adelante, la Convención) que entró en vigor en $1978 .^{29}$

Los regímenes militares que detentaron el poder en los países del Cono Sur a principios de años setenta llevaron a que aumentara el activismo del sidH. La década entre la adopción de la Convención en 1969 y su entrada en vigor en 1978 señaló el descenso de América Latina en el abismo de las violaciones sistemáticas a los derechos humanos de parte de Estados determinados a forzar violentamente una extremada reestructuración social. ${ }^{30}$ La naturaleza de la opresión que se extendía en la zona, que implicaba abiertas declaraciones de guerra de regímenes militares contra supuestos opositores, invocando la "seguridad nacional" cuando justificaban estados de emergencia prolongados, y la secrecía en torno a los métodos empleados por los agentes del Estado -en la forma de centros clandestinos de tortura y de la práctica de desapariciones forzadas-, dejaba sin efecto los mecanismos existentes para la petición individual a la Comisión. ${ }^{31}$ El objetivo principal de la Comisión era entonces no investigar violaciones aisladas,

${ }^{29}$ La Convención se aprobó en San José de Costa Rica el 22 de noviembre de 1969, y entró en vigor el 18 de julio de 1978. Cuenta actualmente veinticinco Estados partes, con algunas excepciones conspicuas. Estados Unidos firmó la Convención de 1977, pero no la ha ratificado. Canadá no es signatario de la Convención, ni la mayor parte de los países anglófonos del Caribe. En lo que se refiere a estas naciones, el SIDH evalúa sus registros a la luz de sus compromisos sobre derechos humanos ante la Declaración Americana de los Derechos y Deberes del Hombre, de la que todos son signatarios. Douglass Cassel, "A United States View of the Inter-American Court of Human Rights”, en Antonio A. Cançado Trindade (ed.), The Modern World of Human Rights, San José, Inter-American Institute of Human Rights, 1996.

${ }^{30}$ Guillermo A. O'Donnell, Modernization and Bureaucratic-Authoritarianism: Studies in South American Politics, Berkeley, Institute of International Studies, University of California Press, 1973.

${ }^{31}$ Para ejemplos de negaciones rotundas de hechos afirmados en peticiones, véase IACHR Reports 20/78, 21/78, 22/78 y 27/78 (Argentina), y IACHR's Annual Report 1979-1980. 
sino documentar y reportar el suceso de violaciones graves a los derechos humanos a fin de ejercer presión para mejorar la situación general de los derechos humanos en el país afectado. Por medio de investigaciones de campo e informes por país, la principal contribución de la Comisión tomó la forma de un impacto indirecto en la actividad normativa, sobre todo relacionada a rebatir la doctrina de seguridad nacional. ${ }^{32}$

Una Comisión más activa fue resultado en parte de cambios en la política interna de Estados Unidos, que abrieron un contexto más permisivo para las gestiones sobre derechos humanos. El escollo en Vietnam y el impulso creciente detrás del escándalo de Watergate, junto a la implicación de Estados Unidos en el golpe al gobierno de Allende en Chile, precipitaron un cambio notable en la política exterior estadounidense. La implicación de la cia en operaciones encubiertas pasaron al creciente escrutinio del Congreso y del público, lo que llevó a que el Congreso revisara cada vez más la política externa. Se aprobaron varias leyes que limitaban la esfera ejecutiva de iniciativas independientes de Estados Unidos. Esto también animó algún apoyo para la CIDH, visible, por ejemplo, en la ampliación de fondos para la Comisión por parte del Congreso. ${ }^{33}$ Asimismo, la década de 1970 también atestiguó la aparición de organizaciones de derechos humanos (ODH) no gubernamentales como respuesta a las dictaduras militares autoritarias y al fracaso de naciones democráticas para ofrecer apoyo a las víctimas de abusos contra los derechos humanos. Conforme florecía la red internacional de derechos humanos cimentada en normas legales internacionales preexistentes, buscaba influir en la opinión internacional por medio de la difusión de

${ }^{32}$ La Comisión elaboró investigaciones de campo en Chile (julio-agosto de 1974) y en Argentina (septiembre de 1979), las cuales rindieron en una serie de reportes del país en el caso de Chile $(1974,1976,1977)$ y de un solo reporte en el caso de Argentina (1980), en que se documentó el uso sistemático de la tortura y las "desapariciones forzadas". Un ejemplo reiterado de la influencia de la Comisión es el reporte de 1978 sobre Nicaragua, que deslegitimó eficazmente al régimen de Somoza. Padilla, "The Inter-American System for the Promotion and Protection of Human Rights”, p. 398.

${ }^{33}$ David Forsythe, art. cit., p. 85. 
información y de la denuncia de gobiernos que vulneraban los derechos. ${ }^{34}$

Durante la presidencia de Carter, la creciente oposición política interna en Estados Unidos convergió de maneras importantes con la aparición de oDH como francos grupos de presión. En conjunto con los esfuerzos de la administración de Carter para señalar un cambio ante el pasado, las políticas estadounidenses de derechos humanos cambiaron considerablemente. ${ }^{35}$ Con todo, aunque las políticas de esa administración sobre derechos humanos se canalizaban con frecuencia a la CIDH, el impacto inmediato real de estas presiones estuvo bastante limitado. ${ }^{36}$ Esto se debía en buena medida a la importancia de las fuerzas internas para explicar el cambio en derechos humanos. Considérese el caso de la visita de la CIDH a Argentina en 1979. Luego del golpe de 1976, el Departamento de Estado de Estados Unidos apeló a Argentina en favor de los ciudadanos estadounidenses que habían sido arrestados o secuestrados. Luego en diciembre de 1976 el Departamente de Estado informó al Congreso estadounidense que el "el Departamento de Estado y nuestra embajada en Buenos Aires

${ }^{34}$ Kathryn Sikkink, "The Emergence, Evolution, and Effectiveness of the Latin American Human Rights Network”, en Elizabeth Jelin y Eric Hershberg (eds.), Constructing Democracy: Human Rights, Citizenship and Society in Latin America, Boulder, Westview, 1997, pp. 59-84.

${ }^{35}$ Forsythe enlista varias políticas clave que tuvieron relevancia directa en la relación de Estados Unidos con el siDH: "firmar la Convención Americana sobre Derechos Humanos; apoyar una ofensiva diplomática para obtener otras firmas y ratificaciones; castigar públicamente a los transgresores de derechos humanos, como Brasil, Guatemala, Uruguay y Argentina; apoyar el aumento en las asignaciones para la Comisión; trabajar de cerca con el presidente activo de la Comisión; manejar alguna asistencia externa de Estados Unidos en nombre de los derechos; tomar en cuenta los derechos humanos al votar en el Banco Interamericano de Desarrollo y otros bancos multilaterales; mantener una diplomacia discreta en favor de las víctimas de la política; y captar la ayuda de la Comisión, entre otros órganos de la oEA, en un intento para librar a Nicaragua del presidente Anastasio Somoza”. David Forsythe, art. cit., p. 90. Véase también: Tom Farer, "The Rise of the Inter-American Human Rights Regime”, pp. 537-538.

${ }^{36}$ Para una perspectiva de mediano plazo sobre los cambios institucionales durante la época de Carter, véase Kathryn Sikkink, Mixed Signals: U.S. Human Rights Policy and Latin America, Ithaca, Cornell University Press, 2004. 
habían discutido repetidamente el asunto de los derechos humanos con funcionarios del gobierno de Argentina durante 1976". ${ }^{37}$ La postura de Estados Unidos se endureció en cuanto Carter tomó la presidencia en enero de 1977, y "Argentina vino a simbolizar el enfoque de confrontación de los derechos humanos". ${ }^{38}$ Funcionarios del Departamento de Estado visitaron Argentina en varias ocasiones para discutir la situación de derechos humanos, lo que culminó con la visita del secretario de Estado Cyrus Vance en noviembre de 1977, cuando envió una lista de miles de personas desaparecidas al gobierno argentino, y con la del secretario adjunto de Estado, David Newsom, a principios de 1978. Más aún, en julio de 1977, el Congreso interrumpió todo apoyo militar y ventas a Argentina (aunque no entrase en efecto sino hasta septiembre de 1978), y en julio de 1978, el Departamento de Estado indicó que no podría recomendar la financiación bancaria de exportaciones e importaciones (EXIM) ${ }^{39}$ A su vez, durante el mismo periodo Estados Unidos comenzó a abstenerse de votar sobre los préstamos a Argentina desde el Banco Interamericano de Desarrollo. En septiembre de 1978, con todo, el Departamento de Estado aprobó el financiamiento EXıM, a cambio, al parecer, de la conformidad del gobierno argentino con la visita de la CIDH. ${ }^{40}$

Puede resultar desconcertante en principio que la junta argentina aceptara la visita de la CIDH. ${ }^{41}$ Aún así, la evidencia sugiere

${ }^{37}$ David Weissbrodt y María Luisa Bartolomei, "The Effectiveness of International Human Rights Pressures: The Case of Argentina, 1976-1983”, Minnesota Law Review, vol. 75, núm. 3, febrero de 1991, p. 1020.

${ }^{38}$ Guest, Behind the Disappearances, p. XIV.

${ }^{39}$ Weissbrodt y Bartolomei, art. cit.

${ }^{40}$ Guest, Behind the Disappearances, p. 172.

${ }^{41}$ Lars Schoultz, Human Rights and United States Policy toward Latin America Princeton, Princeton University Press, 1981; Sikkink, Mixed Signals. La visita de los miembros y del equipo de la CIDH durante dos semanas en septiembre de 1979 llamó atención considerable, nacional e internacionalmente, dado que centraba el reflector en el historial de derechos humanos del régimen militar. La CIDH se encontró con el presidente Videla, otros funcionarios del gobierno, delegados de diversos partidos políticos, comisionados de reconocidas organizaciones comerciales, representantes de organizaciones de derechos humanos argentinas y abogados. Antes de que la Comisión hubiese visitado Argentina, recibió informes de representantes 
que a fines de 1978 la junta había eliminado a la oposición política de manera que había comenzado ya a modificar sus políticas represivas. Incluso antes de la visita de la CIDH, las autoridades de Argentina parecían haber mejorado las condiciones de reclusión de los detenidos políticos, a la vez que los reportes de maltratos se habían reducido. El presidente Videla, como jefe de la junta militar, parece haber calculado que el régimen iba a poder controlar los hallazgos de la CIDH para ventaja del propio régimen. Esto había provocado una división en la junta militar, entre la línea dura, de un lado, y aquellos miembros de la junta que estaban a favor de suavizar su gobierno y que enfatizaban la importancia de mejorar la presencia internacional del régimen. $\mathrm{Al}$ aceptar la visita de la CIDH, la "línea suave" parecía haber vencido en las pugnas internas entre las distintas facciones del régimen militar. En lo que se refiere al impacto en la situación de los derechos humanos en Argentina, tras la visita de la CIDH el número de desapariciones pareció disminuir. Con todo, la causa exacta del cese aparente de las desapariciones luego de la visita sigue en discusión. Kathryn Sikkink, por ejemplo, sostiene que la clara mejoría en la situación de derechos humanos en Argentina se debió a presiones internacionales y al resultado de un cambio en el ambiente político luego de que asistiera la CIDH. ${ }^{42}$ Aún así, como se anotó, hay evidencia que sugiere que la declarada "guerra contra la subversión" de los militares estaba casi completa, de manera que para la visita de la Comisión las desapariciones ya no resultaban necesarias. De hecho, en septiembre de 1979 el gobierno militar declaraba que había ganado la guerra contra los "subversivos". A este respecto, si acaso la visita de la CIDH tuvo algún efecto inmediato, fue el de reforzar la posición de la línea dura de la junta en el corto plazo, al menos mientras que la visita no fuera contraproducente y atrajera mala publicidad para el régimen.

Al final, no se hizo nada ante el reporte de la CIDH sobre la situación de derechos humanos en Argentina cuando se presentó a

de varios grupos de derechos humanos, y durante su visita la Comisión recabó numerosos testimonios sobre violaciones a los derechos humanos de parte de organizaciones de derechos humanos locales.

${ }^{42}$ Sikkink, Mixed Signals. 
la Asamblea General de la oeA en noviembre de $1980 .{ }^{43}$ Conforme la nueva administración de Reagan se distanciaba explícitamente de las políticas de derechos humanos de Carter, las relaciones entre Estados Unidos y la Junta Militar de Argentina mejoraban considerablemente. Esto, junto con la diplomacia activa de los diplomáticos argentinos en la oeA y el apoyo del Secretario General de la oEA, entonces un argentino, Alejandro Orfila (1975-1984), llevó a la inacción de la OEA. Sin embargo, mientras que las políticas internas de esta organización pueden haber prevenido la condena de Argentina de parte de los Estados miembros, para la propia CIDH la visita a este país representa un momento definitorio en el desarrollo de su identidad como institución de derechos humanos independiente y funcional. ${ }^{44}$

Para comienzos de la década de 1980, la administración de Reagan intensificó la retórica de la Guerra Fría, a la vez que sus políticas beligerantes reavivaban los conflictos en Centroamérica. Según se apunta en la doctrina Kirkpatrick, Estados Unidos buscaba acercarse a los regímenes militares latinoamericanos; esto se acompañó de clara hostilidad hacia las instituciones multilaterales. ${ }^{45}$ Los conflictos centroamericanos y las violaciones masivas a los derechos humanos destacaron así los límites de la estrategia de denuncia de la CIDH y su honda integración a las relaciones entre Estados Unidos y América Latina. Como observa Farer, semejante estrategia "funcionaba mejor cuando los infractores de los derechos humanos confiaban en el apoyo interno de grupos no del todo insensibles a las demandas morales de la opinión

${ }^{43}$ IACHR, Report on the Situation of Human Rights in Argentina, 11 de abril de 1980.

${ }^{44}$ La CIDH había realizado muy pocas visitas a países antes de Argentina; esta visita sentó un precedente para la Comisión en términos de su modus operandi. De cualquier forma, para las repercusiones negativas que hubo para la CIDH en el corto plazo, luego de publicado el reporte, véase Weissbrodt y Bartolomei, art. cit.

${ }^{45}$ Farer destaca el contraste con los años de Carter: "Donde Carter había visto instituciones intergubernamentales, regionales o globales, como colaboradores del orden global, su sucesor se inclinaba a mirarlas como impedimentos para el ejercicio del poder en el interés nacional". Farer, "The Rise of the Inter-American Human Rights Regime”, pp. 541-542. 
pública internacional o cuando afectaba positivamente el tono y la sustancia de la diplomacia de las grandes potencias". ${ }^{46}$ En efecto, la explosión de las violaciones a los derechos humanos en Centroamérica (y el asesinato de ciudadanos estadounidenses en la región) aumentó la preocupación pública y el escrutinio del Congreso en Estados Unidos. En la práctica, con todo, las leyes adoptadas de acuerdo a cada país y orientadas a condicionar la ayuda de Estados Unidos para la actuación sobre los derechos humanos se cumplieron poco. Y, en cada caso, el segundo mandato de Reagan ignoró o evadió la legislación que condicionaba la ayuda extranjera de derechos humanos con la intención de reafirmar el control ejecutivo de la política exterior.

\section{El SIDH y la democratización}

El final de la Guerra Fría en el contexto regional de América Latina constituyó una combinación tanto de cambios significativos como de continuidad. Por una parte, conforme se extinguían los años ochenta los regímenes autoritarios a lo largo de América Latina cedían su lugar a gobiernos elegidos democráticamente. Se compartían ahora más valores democráticos en América Latina que en cualquier otro momento desde el comienzo de la Guerra Fría. Los instrumentos para la acción colectiva disponibles para las instituciones regionales se hicieron más fuertes y se combinaban con un conjunto general de principios al que los actores externos podían contribuir al fomento de la democracia. ${ }^{47}$ La tolerancia para semejante acción externa también se incrementó. ${ }^{48}$ Claramente, la aparición de una norma de democracia regional debe entenderse en el contexto del final de la Guerra Fría, que alteró el panorama geopolítico en América Latina y en particular propició cambios en las percepciones de seguridad en quienes formulan

${ }^{46}$ Loc. cit. Véase también Sikkink, Mixed Signals.

${ }^{47}$ La doctrina de Clinton de ampliación democrática representa una articulación de estos principios.

48 Tom Farer (ed.), Beyond Sovereignty: Collectively Defending Democracy in the Americas, Baltimore, The Johns Hopkins University Press, 1996. 
las políticas en Estados Unidos. En el periodo inmediato de post Guerra Fría, la promoción y la defensa de la democracia se volvió, en palabras de uno de los participantes, "prioridades de política exterior" ${ }^{49}$ para los países de la región. Y, con todo, por la otra parte, pese a institucionalización regional, que apuró el paso durante los años noventa y que conoció un número sin precedente de compromisos declaratorios para apoyar la democracia representativa en la región, las asimetrías geopolíticas fundamentales que caracterizan las relaciones interamericanas persistieron, de aquí perduró el recelo de agendas políticas intervencionistas. En otras palabras, el contexto general de las relaciones entre Estados Unidos y América Latina no experimentó cambios tan profundos como proclamaba el discurso político dominante de la década de 1990 confiadamente. La transformación del ambiente de seguridad estaba lejos de completarse, a la vez que se expandían las preocupaciones por el terrorismo y la guerra contra las drogas. Además, la transformación de la economía global aumentó la vulnerabilidad de muchos países latinoamericanos económicamente más débiles.

Con la transición a la democracia aumentó la voluntad entre los Estados para declarar formalmente la adhesión a los estándares internacionales. Esto puede verse en las numerosas ratificaciones de la Convención Americana y en la creciente aceptación de la jurisdicción de la Corte Interamericana. ${ }^{50}$ Durante el periodo de los regímenes autoritarios, ninguno de los grandes infractores

${ }^{49}$ Heraldo Muñoz, "The Right to Democracy in the Americas", Journal of Interamerican Studies and World Affairs, vol. 40, núm. 1, 1998, pp. 1-18.

${ }^{50}$ Argentina ratificó la Convención en 1984 y aceptó la jurisdicción de la Corte ese mismo año. Uruguay procedió igual en 1985, Paraguay en 1989 (aceptó la jurisdicción de la Corte en 1993), Chile en 1990 y Brasil en 1992 (aceptó la misma jurisdicción en 1998). En contraste, Pasqualacci argumenta que países como Perú y Guatemala parecen haber ratificado la Convención como un gesto sin intención firme de cumplir sus disposiciones. (Jo M. Pasqualucci, "Preliminary Objections before the Inter-American Court of Human Rights: Legitimate Issues and Illegitimate Tactics", Virginia Journal of International Law, vol. 40, núm. 1, 1999, p. 6.) Mas, aunque no hay equivalencia automática entre ratificación y cumplimiento, la ratificación evidencia aun así la importancia para los Estados en procesos de democratización de la convergencia con las normas internacionales de de derechos humanos. 
-Argentina, Chile, El Salvador, Guatemala, Uruguay y Paraguayparticipaba en la Convención, y a todos los había investigado varias veces la Comisión. Algunos Estados se sirvieron del SIDH para consolidar su democracia (muy claramente la Argentina de Alfonsín) y para marcar un rompimiento con el pasado. De aquí que el importante fortalecimiento institucional del sistema regional de derechos humanos durante los años noventa no se explique meramente por las relaciones cambiantes de Estados Unidos y América Latina, sino también por cambios políticos internos en las nuevas democracias latinoamericanas. ${ }^{51}$

El fortalecimiento institucional y la expansión normativa del Sistema Interamericano de Derechos Humanos sucedieron en un ambiente de procesos democráticos generalizados en la región. En este espacio donde los golpes militares solían ser una conducta aceptable en el juego político, ${ }^{52}$ la aparición de una norma democrática robusta es un evento notorio por sí mismo. Con la adopción del Protocolo de Cartagena en 1985 -que enmendaba la Carta de la oEA- los Estados miembros proclamaron la promoción y consolidación de la democracia representativa como un "propósito esencial" de la organización. ${ }^{53}$ Fue, con todo, la 20a Asamblea

${ }^{51}$ Aunque la propagación de gobiernos electos señaló una mejora importante en la situación de los derechos humanos, siguieron llegando casos de graves e indiscutibles violaciones a los derechos humanos a la Comisión. Además, en la negociación con gobiernos formalmente democráticos, había expectativa de algo de cooperación con el sistema, con que se sustituiría a la pronta negativa y al rechazo con "la plena defensa legal de sus posiciones sobre asuntos de hecho y de derecho”. La presión sobre el Sistema Interamericano también provino de la comunidad de derechos humanos, que, en un ambiente cada vez más legal, demandaba más de la Comisión que una simple resolución a favor de las víctimas a las que representaban. Como anota Farer, "buscaban requerimientos y desagravios que sólo se podían asegurar en la Corte Interamericana”. En otras palabras, ante el apremio de "comentaristas, abogados y gobiernos, la Comisión [comenzó] gradualmente a avanzar hacia una especie de existencia más orientada a los casos, conque atraía más labores a la Corte". Farer, "Rise of the Inter-American Human Rights Regime".

52 Ellen L. Lutz y Kathryn Sikkink, "International Human Rights Law and Practice in Latin America”, International Organization, vol. 54, núm. 3, 2000, p. 658.

${ }^{53}$ La enmienda de 1985 reiteró el objetivo fundacional de la Organización: "promover y consolidar la democracia representativa", aunque se agregase también una prevención: "con el respeto debido al principio de no intervención”. 
General (AG), celebrada en Asunción, Paraguay, en 1990, la que marcó el inicio de un compromiso emergente de llevar las declaraciones a la práctica. En el encuentro de la AG, se pidió al Secretario General que fundara la Unidad para la Promoción de la Democracia (UPD), a la que se encomendó que proveyera a los Estados con asistencia para preservar y fortalecer las instituciones democráticas y los procedimientos. Se le dio seguimiento en junio de 1991, en la 21 asamblea General en Santiago de Chile, donde se adoptó el "Compromiso de Santiago con la Democracia y la Renovación del Sistema Interamericano” y la Resolución 1080, ${ }^{54}$ que autorizó a los Estados a solicitar una convocatoria inmediata "para adoptar las decisiones que estime conveniente, de acuerdo con la Carta y la ley internacional" como respuesta a alteraciones autoritarias en cualquier Estado. Aunque no se acordaron medidas concretas a las que la ofA recurriese en caso de una "interrupción" del proceso democrático, esto significó un paso adelante de los Estados miembros de la oeA respecto de su posición tradicional sobre la no intervención. Con todo, la resolución 1080 define la democracia representativa como un ejercicio de soberanía y como una condición "indispensable para la estabilidad, la paz y el desarrollo de la región”. La Declaración de Santiago, entonces, representa un cambio en la definición de intervención, que siguió siendo ilegal en tanto que llevada a cabo unilateralmente, pero aceptable como mecanismo multilateral. ${ }^{55}$

${ }^{54}$ El Compromiso de Santiago también preparó un plan general de acción para la década de 1990 en una amplia gama de otras cuestiones, que incluían la reducción de desigualdades económicas y sociales, la promoción de la liberalización del mercado y las asesorías "sobre seguridad hemisférica a la luz de las nuevas condiciones".

55 Después de que el Compromiso de Santiago y la Resolución 1080 acordaran una serie de principios, se adelantó un poco sobre las líneas para la acción concreta en la 22a Asamblea General de la oEA en Nassau, Bahamas, en mayo de 1992. Se proponía que la "incorporación de nuevas provisiones en la Carta de la oEA sobre la viabilidad de suspender los gobiernos de los Estados miembros cuando sucediera una interrupción repentina o irregular del proceso institucional democrático". Esta propuesta se aprobó en diciembre de 1992 con otra enmienda a la Carta de la oEA (Protocolo de Washington), que entró en vigor tras la ratificación de los Estados miembros. El Protocolo de Washington autorizó la suspensión, 
En concreto, el procedimiento de las Cumbres de las Américas surgió como un foro importante que fomentaba la agenda de la democracia regional. Se había originado como una propuesta de Estados Unidos. El proceso de Cumbres, según nació en 1994, se llevó a cabo fuera del marco de la oEA. Si bien esta iniciativa la motivaba una percepción de que la oea necesitaba una profunda reforma a la luz de lo que se creía ser las nuevas circunstancias de la región, el procedimiento de Cumbres se fue incorporando a la jurisdicción oficial de la oeA. ${ }^{56}$ Desde la Primera Cumbre de las Américas en Miami (1994), los Estados americanos han buscado promover la idea de una "comunidad de sociedades democráticas". ${ }^{57}$ La Cumbre de Santiago (1998) se organizó sobre esta idea, mientras que la Cumbre de Quebec en abril de 2001 -arrancada como la Cumbre de la Democracia ${ }^{58}$ - adoptó una cláusula democrática cuyos términos establecían que "cualquier alteración o ruptura inconstitucional del orden democrático en un Estado del Hemisferio constituye un obstáculo insuperable para la participación del Gobierno de dicho Estado en el proceso de Cumbres de las Américas". ${ }^{59}$ Durante

con dos tercios de los votos de los Estados miembros, de todo gobierno que hubiese tomado el poder por la fuerza. La Resolución 1080 de la Asamblea General de la oEA y el Protocolo de Washington buscaban identificar a las Américas como a una comunidad democrática. También proveen los mecanismos para la posible acción colectiva de la oEA en el caso de "interrupciones" del proceso democrático de los Estados miembros. Pero estos instrumentos se refieren sólo a las interrupciones del orden democrático institucional y no sirven para proteger contra las amenazas a la democracia que no sean golpes de Estado o pronunciamientos militares.

56 Andrew F. Cooper y Jean-Philippe Thérien, "The Inter-American Regime of Citizenship: Bridging the Institutional Gap between Democracy and Human Rights”, Third World Quarterly, vol. 25, núm. 4, 2004, p. 736.

${ }^{57}$ Aunque desde hacía mucho se aspiraba a declararla, la idea de una "comunidad de democracias" en las Américas se va tornando cada vez más institucionalizada. Véanse las Conferencias Ministeriales de la Comunidad de Democracias (http:/ / www.cdemo.cl) y el Consejo para una Comunidad de Democracias (http:// www.ccd21.org), con un liderazgo latinoamericano importante, aunque más bien global en perspectiva.

58 Andrew F. Cooper, "The Quebec City 'Democracy Summit”, Washington Quarterly, vol. 24, núm. 2, 2001, pp. 159-171.

59 Andrew F. Cooper y Thomas Legler, "The OAs Democratic Solidarity Para- 
la Cumbre de Quebec también se dispuso el marco para la redacción de una Carta Interamericana Democrática. Luego de pocos meses de negociación, se adoptó por fin la Carta el 11 de septiembre de 2011, en una sesión especial de la Asamblea General de la oeA celebrada en Lima, Perú. La Carta Democrática Interamericana ${ }^{60}$ ampliaba las condiciones bajo las cuales se puede suspender de la oEA a un Estado miembro por "comportamiento antidemocrático”. Su adopción señaló la culminación de un intenso periodo regional de actividad normativa en América Latina conforme la doctrina regional de defensa de la democracia evolucionó a una obligación normativa acompañada de una nueva determinación para implementarla por efecto de la acción colectiva. Las normas fundamentales del régimen democrático se aclaran en el artículo 1 de la Carta Democrática: "Los pueblos de América tienen derecho a la democracia y sus gobiernos la obligación de promoverla y defenderla". ${ }^{61}$

De esta manera, de meros compromisos declaratorios, los Estados miembros de la oeA adoptaron mecanismos para atender

digm: Questions of Collective and National Leadership", Latin American Politics and Society, vol. 43, núm. 1, 2001, pp.103-126.

${ }^{60}$ Sobre la negociación de la Carta Democrática Interamericana, véase Andrew F. Cooper, "The Making of the Inter-American Democratic Charter: A Case of Complex Multilateralism”, International Studies Perspectives, vol. 5, núm. 1, 2004, pp. $92-113$.

${ }^{61} \mathrm{El}$ artículo 3 de la Carta Democrática define algunos de los "elementos esenciales" de la "democracia representativa": "el respeto a los derechos humanos y las libertades fundamentales; el acceso al poder y su ejercicio con sujeción al estado de derecho; la celebración de elecciones periódicas, libres, justas y basadas en el sufragio universal y secreto como expresión de la soberanía del pueblo; el régimen plural de partidos y organizaciones políticas; y la separación e independencia de los poderes públicos". Por su parte, el artículo 7 sostiene que "La democracia es indispensable para el ejercicio efectivo de las libertades fundamentales y los derechos humanos, en su carácter universal, indivisible e interdependiente, consagrados en las respectivas constituciones de los Estados y en los instrumentos interamericanos e internacionales de derechos humanos". A su vez, el artículo 23 declara que "Los Estados Miembros son los responsables de organizar, llevar a cabo y garantizar procesos electorales libres y justos". Véase de Thomas Franck, "The Emerging Right to Democratic Governance"; "Democracy as a Human Right"; "The Democratic Entitlement". 
alteraciones del orden democrático en la región. Aunque avanzaban sobre normas institucionales bien afianzadas, los eventos de la década de 1990 constituyen en efecto un cambio normativo en el panorama regional institucional. En una región donde las formas interestatales de cooperación se han diseñado en torno a la noción de soberanía nacional, el trabajo hacia un marco institucional normativamente más intrusivo llevó a un cambio importante en los principios que apuntalan el orden regional. De estar basado en el principio tradicional de la coexistencia de los Estados, con la debida consideración a la soberanía nacional, la lógica subyacente de la cooperación estatal experimentó un cambio hacia un sistema basado en nociones solidaristas ${ }^{62}$-"dondequiera que se amenace a la democracia, la comunidad debería actuar"con distintos elementos coercitivos. Estos cambios caracterizaron los acontecimientos políticos en el plano regional en los años noventa; se han interpretado como una "transformación de la soberanía, gradual y acaso irreversible, ante los temas de derechos humanos y democracia”. ${ }^{63}$ Todo esto representó una voluntad creciente de los Estados para establecer una conexión entre valores democráticos e instituciones de gobernanza regional. ${ }^{64}$ Tales compromisos han coincidido, además, con varios esfuerzos multilaterales emprendidos por el Sistema Interamericano de Derechos Humanos en respuesta a los eventos en Haití (1991), Perú (1992, 2000), Guatemala (1993), Paraguay (1996, 1999) y Venezuela (2002). Aún así, aunque la oea ha tenido algunos éxitos con sus mecanismos informales de resolución de conflictos, ${ }^{65}$ las Cumbres de las Américas recientes (en Argentina en 2005, Trinidad y

${ }^{62}$ Sobre la noción de solidarism véase Bull, The Anarchical Society.

${ }^{63}$ Kathryn Sikkink, "Reconceptualizing Sovereignty in the Americas: Historical Precursors and Current Practices”, Houston Journal of International Law, vol. 19, 1996-1997, p. 705.

${ }^{64}$ Cooper y Legler, "OAs Democratic Solidarity Paradigm”.

65 Andrew F. Cooper y Thomas Legler, "A Tale of Two Mesas: The oAs Defense of Democracy in Peru and Venezuela”, Global Governance, vol. 11, núm. 4, 2005; Andrew F. Cooper y Thomas F. Legler, Intervention without Intervening? The oAs Defense and Promotion of Democracy in the Americas, Basingstoke, Palgrave Macmillan, 2006. 
Tobago en 2009 y Colombia en 2012) evidencian las directrices políticas cambiantes en la región, particularmente en las relaciones entre Estados Unidos y América Latina, que desafían los juicios que proponen una convergencia regional en los valores políticos. Volveremos a esta tendencia en la siguiente sección. ${ }^{66}$

\section{El carácter transnacional del SIDH}

La Carta original de la oeA de 1948 declaraba que la solidaridad regional se basaba en el respeto por el gobierno democrático y proclamaba la importancia de los derechos individuales. Sin embargo, las normas asociadas con la democracia y los derechos humanos se han desarrollado a la par del principio de soberanía en las Américas, con frecuencia con inevitables tensiones institucionales y políticas. Tradicionalmente estas tensiones se han resuelto en favor de la soberanía del Estado, como se evidencia en la nula respuesta de las instituciones regionales a las décadas de orden antidemocrático y de violaciones generalizadas de los derechos humanos como política estatal en la región. Con todo, durante la etapa final de la Guerra Fría, y en los noventa en particular, se puede observar una expansión significativa de instituciones regionales y cambios importantes en la voluntad, enfoque y densidad de la gobernanza regional en América. ${ }^{67}$ Para muchos de los nuevos regímenes democráticos en la región, la pregunta sobre cómo lidiar con los abusos a los derechos humanos de gobiernos anteriores

${ }^{66}$ Para un recuento del impacto del contexto regional cambiante sobre los esfuerzos para promover la democracia y las implicaciones para las relaciones entre Estados Unidos y América Latina, véase Par Engstrom y Andrew Hurrell, "Why the Human Rights Regime in the Americas Matters", en Mónica Serrano y Vesselin Popovski (eds.), Human Rights Regimes in the Americas, Tokio, United Nations University Press, 2010. Véase además: Andrew Hurrell, "Hegemony and Regional Governance in the Americas", en Louise Fawcett y Mónica Serrano (eds.), Regionalism and Governance in the Americas: Continental Drift, Basingstoke, Palgrave Macmillan, 2005. Eventos recientes en Honduras, donde un golpe militar depuso al presidente del país democráticamente electo, ilustran las dificultades de la oEA para llevar las normas a la práctica.

${ }^{67}$ Louise Fawcett y Mónica Serrano (eds.), op. cit. 
vendría a definir la naturaleza y calidad de las nuevas democracias. La evolución del sistema de derechos humanos quedó sujeta entonces a dicha cuestión. En particular, los casos que enfrentó el sistema durante este periodo concernían sobre todo a la práctica de las desapariciones forzadas en regímenes autoritarios, el estatus de las garantías judiciales en estados de emergencia, la admisión legal y política de leyes de amnistía, la provisión de arreglos internos para las víctimas de derechos humanos, asuntos de rendición de cuentas de abusos de derechos humanos pasados y el derecho al acceso individual al sistema regional de derechos humanos. ${ }^{68}$

El desafío a la naturaleza tradicionalmente pluralista del orden regional podría verse en el rumbo hacia un marco de gobernanza transnacional en el tema de los derechos humanos. ${ }^{69} \mathrm{El}$ SIDH ha evolucionado en un régimen legal que provee a los individuos y a los grupos con mecanismos supranacionales para desafiar las actividades internas de sus propios gobiernos. El sistema regional ha desarrollado un conjunto de normas de derechos humanos cada vez más extenso e intrusivo, el cual legitima la preocupación internacional por el bienestar general de los individuos y por las prácticas estatales de los derechos humanos. ${ }^{70}$ Semejantes eventos han sucedido a pesar de la pugna del Sistema Interamericano en el pasado ante órdenes autoritarios a lo largo del continente. Aquella ganó empuje con el retorno del orden democrático formal y continúa desafiando a los gobiernos democráticos mientras que el legado del autoritarismo acecha a las comunidades en transición; y busca responsabilizar a los gobiernos por sus fallas

68 Due Process of Law Foundation, Victims Unsilenced: The Inter-American Human Rights System and Transitional Justice in Latin America, Washington, D. C., Due Process of Law Foundation, 2007.

${ }^{69}$ Estos acontecimientos regionales deberían considerarse en el contexto más amplio de la creciente transnacionalización de los derechos humanos. Véase, por ejemplo, Alison Brysk, Globalization and Human Rights, Berkeley, University of California Press, 2002; Alison Brysk y Gershon Shafir, People Out of Place: Globalization, Human Rights and the Citizenship Gap, Londres, Routledge, 2004.

${ }^{70}$ David Harris, "Regional Protection of Human Rights: The Inter-American Achievement", en David Harris and Stephen Livingstone (eds.), The Inter-American Human Rights System, Oxford, Clarendon Press, 1998. 
para estar a la altura de los ideales democráticos. Hay tres rasgos en el sendero hacia la transnacionalización del sistema regional de derechos humanos de un sistema intergubernamental clásico: $i$ ) la expansión e intromisión en aumento en las normas regionales ocupadas de los derechos humanos y la democracia política; ii) el creciente pluralismo de la creación de normas en lo que se refiere a la pluralidad de actores que participan en los foros; y iii) fortificar la aplicación a la vez que las estructuras regionales se van fortaleciendo y aplicándose para la implementación de las normas regionales.

En primer lugar, en términos de expansión normativa, una de las modificaciones regionales más importantes al derecho internacional que vino con la entrada en vigor de la Convención fue la instauración de un derecho de petición privada, con que se fortaleció legalmente el acceso a los individuos al sistema de derechos humanos. Para que la Corte atendiera un caso, los procedimientos ante la Comisión deben haberse completado; esta provisión ubica a la Comisión en el centro del Sistema Interamericano. ${ }^{71}$ Con todo, debe notarse que sólo los Estados partícipes de la Convención y la Comisión tienen el derecho de enviar casos a la Corte, mientras que los individuos no están en posición de hacerlo. Entonces, aunque la Convención establece el acceso individual al Sistema Interamericano, "la idea enraizada de que el derecho internacional regula las relaciones entre los Estados se refleja en la regla de que los individuos en general no tienen derecho de petición ante los tribunales internacionales". ${ }^{72}$ En su lugar, el mecanismo que se adoptó consiste en que cualquier persona o grupo de personas, o cualquier entidad no gubernamental legalmente reconocida en uno o más de los Estados miembros puede presentar peticiones a la Comisión alegando violaciones de la Convención por los Estados partícipes. ${ }^{73}$

${ }^{71}$ Luego de que la Comisión reconozca una petición o comunicación como admisible, investiga los hechos denunciados en tanto que violaciones a la Convención y prepara un reporte preliminar, con propuestas y recomendaciones, a los Estados acusados. La Convención faculta a la Comisión y al Estado para enviar el caso a la Corte dentro de tres meses.

72 Medina Quiroga, The Battle of Human Rights, p. 169.

${ }^{73}$ La CIDH se está haciendo cada vez más accesible a los demandantes. Entre 
Aunque el poder de la Corte para decidir sobre un caso que se le turne está condicionado por que los Estados partes de la controversia acepten su jurisdicción, la competencia para juzgar Estados por infracciones a los derechos humanos y para mandar a los Estados a compensar a las víctimas ha "transformado virtualmente a la [Corte] en una especie de corte internacional criminal". ${ }^{74}$ Más aún, la Corte puede pronunciarse sobre la compatibilidad de la legislación nacional con la Convención. El papel de la ley de derechos humanos en la determinación de hechos políticos trae a colación los criterios establecidos por el sistema con los cuales se juzga la legitimidad del comportamiento de los Estados. Estos definen las normas con que los gobiernos pueden hacerse responsables ante sus ciudadanos, y ante otras instancias. En particular, el sistema de derechos humanos ha desarrollado instrumentos legales regionales que incorporan cada vez más normas exhaustivas de derechos humanos las cuales buscan regular la relación entre el Estado y los ciudadanos. Dichas acciones tuvieron un impulso con el regreso del orden democrático; en este sentido, la dirección del Sistema Interamericano como un todo quedó ceñida al mantenimiento y progreso de la democracia representativa. Hay con todo una variación regional significativa respecto a la incorporación formal al sistema, como lo reflejó la adopción dispar de instrumentos regionales de derechos humanos en los Estados miembros de la oEA. Entre ellos, notablemente, Estados Unidos, Canadá y los países anglófonos del Caribe no ratificaron la Convención Americana.

otros esfuerzos de participación, los demandantes hoy en día pueden enviar sus denuncias a la Comisión por medio de un procedimiento en línea disponible en su sitio http://www.cidh.org

${ }^{74}$ Cerna, "Structure and Functioning of the Inter-American Court of Human Rights", p. 135. Además, aunque es importante notar que la Corte Interamericana, y el Sistema Interamericano más en general, es una entidad de derechos humanos, conque sólo puede atribuir responsabilidad de Estado por las violaciones, el hecho es que la jurisprudencia del sistema ha tenido un impacto notable en los procedimientos internos judiciales, en particular en países latinoamericanos donde ya han comenzado juicios por crímenes contra la humanidad cometidos por regímenes políticos anteriores. 
En segundo lugar, los actores no estatales, así como las coaliciones transnacionales y transgubernamentales, han tenido un papel considerable en esta expansión normativa de las instituciones regionales. ${ }^{75}$ Conforme crecen la densidad y la complejidad de las instituciones regionales, y a la par que los procesos de regionalización abren nuevos canales de acción política transnacional, el proceso de la creación de normas se vuelve más complejo, disputado y arduo de controlar, incluso para los Estados poderosos. En consecuencia, aunque los Estados siguen siendo actores decisivos en los procesos de institucionalización regional, el pluralismo político creciente que caracteriza al sistema regional ha reforzado la prominencia normativa de los derechos humanos regionales y de las normas de la democracia. Por una parte, el régimen democrático interamericano ha surgido con apoyo activo y esfuerzos de cabildeo intensivo de varios de los Estados miembros más influyentes al igual que de algunos menos influyentes. Aunque los grupos regionales de la sociedad civil jugaron en efecto un papel relevante en el proceso de redacción de la Carta Democrática Interamericana, ${ }^{76}$ el régimen de la democracia opera con poca participación civil y sigue en el molde intergubernamental que típicamente distingue a las instituciones regionales.

El régimen de derechos humanos interamericano, por otra parte, se ha desarrollado de forma independiente con descuido benigno, por decirlo en términos halagüeños, de la mayoría de los Estados miembros frente al sistema. A pesar de, o quizás a causa de, esta indiferencia generalizada aparente, el sistema de derechos humanos ha aprovisionado a grupos diversos de la sociedad civil y a individuos de mecanismos transnacionales de protección de los derechos humanos que buscan responsabilizar a los gobiernos por actividades puramente internas. Así, los procesos de regionalización sobre el orden de los derechos humanos y la democracia han dado a los actores internos oportunidades políticas transnacionales

${ }^{75}$ Roberto Patricio Korzeniewicz y William C. Smith, "Transnational Civil Society Actors and Regional Governance in the Americas: Elite Projects and Collective Action from Below", en Fawcett y Serrano, op. cit.

${ }^{76}$ Cooper, "Making of the Inter-American Democratic Charter". 
y legales para lograr sus intereses. Aunque los actores no estatales sigan fuera de los foros de toma de decisiones del Sistema Interamericano, han adquirido significativa influencia informal gracias a sus actividades, que definen sus propuestas, y a su capacidad, en el contexto de estructuras de gobernanza regional cada vez más desarrolladas y complejas. Desde esta perspectiva, el sistema regional de derechos humanos ha ofrecido una plataforma sobre la que sucede la lucha por los derechos humanos entre los activistas y los Estados.

El tercer aspecto a tener en cuenta atañe al fortalecer el cumplimiento. Luego de la adopción de la Carta de la oeA y de la Declaración Americana, los Estados han elaborado normas de derechos humanos en la Convención Americana sobre los Derechos Humanos y en diversos instrumentos de derechos humanos regionales. Con la incorporación de la Convención al Sistema Interamericano, el régimen regional de derechos humanos comenzó la transición de un régimen meramente promocional a uno caracterizado por la promoción vigorosa con manifiestos mecanismos de aplicación. De promover lineamientos de derechos humanos, con excepciones significativas, la Convención pasó a consolidar normas regionales dentro de un marco procesal con el potencial de dictar decisiones regionales. La Convención "culmina la primera etapa evolutiva del Sistema Interamericano de Derechos Humanos. ${ }^{77} \mathrm{Al}$ obtener compromisos vinculantes de los Estados partes, prescribe un esquema internacional para proteger los derechos humanos". ${ }^{78} \mathrm{Y}$ al hacerlo, el Sistema Interamericano adoptó una aproximación más judicial hacia la promoción y protección de los derechos humanos en la región. ${ }^{79}$

En el contexto de las tensiones acentuadas de la Guerra Fría, a la par de los abusos sistemáticos a los derechos humanos por toda

77 Jack Donnelly, Universal Human Rights in Theory and Practice, Ithaca, Cornell University Press, 1989, pp. 215-217 y 224-225.

78 Jane D. Peddicord, “The American Convention on Human Rights: Potential Defect and Remedies”, Texas International Law Journal, vol. 19, núm. 1, 1984, p. 159.

${ }^{79}$ Verónica Gómez, "The Interaction between the Political Actors of the oAs, the Commission and the Court", en David J. Harris y Stephen Livingstone (eds.), The Inter-American System of Human Rights, Oxford, Clarendon Press, 1998. 
la región, a principios de la década de 1980 este progreso hacia el fortalecimiento del régimen de los derechos humanos habría parecido improbable. Con todo, con la (re)aparición de la democracia en la región se abrió el espacio político para el fomento de los derechos humanos. Un signo de la evolución del sistema de derechos humanos, conforme se extendía su alcance por las distintas cuestiones y los asuntos internos de los Estados, pudo verse en el mayor número de ratificaciones de los instrumentos de derechos humanos y en la mayor aceptación de la jurisdicción de la Corte. El sistema regional, ocupado de la protección de los derechos humanos en las Américas, se ha convertido en un régimen normativamente intrusivo con disposiciones de largo alcance para regular las normas políticas internas y las prácticas de los Estados. El sistema regional de derechos humanos ha motivado un activismo transnacional que conecta concepciones locales de los derechos humanos con lineamientos regionales para influir en los acontecimientos de la política nacional. La nueva apertura en las instituciones regionales ofrece oportunidades a los activistas nacionales y transnacionales de derechos humanos para apresurar un cambio en sus sistemas políticos internos. Los procesos legales y políticos transnacionales resultado de dicha interacción trazan patrones de conducta adecuada que influyen los procesos legales y políticos. De aquí que el "impacto" de las instituciones regionales ocupadas de promover y proteger los derechos humanos y de aposentar el orden democrático radique en su habilidad de definir la naturaleza y dirección de los procesos de democratización y el papel de los derechos humanos en los mismos.

\section{LAS RELACIONES ACTUALES ENTRE Estados Unidos y América Latina y LOS DESAFíos DEL SIDH}

Pese al carácter cada vez más transnacional del sistema regional de derechos humanos, el SIDH prosigue definiéndose por las relaciones interestatales. De esa forma, en un ambiente de institucionalización regional de los derechos humanos y la democracia política durante las décadas recientes, los múltiples retos del 
Sistema Interamericano siguen inscritos en las relaciones actuales de Estados Unidos y América Latina. Pueden notarse tres grupos de desafíos en particular: la persistencia de las violaciones a los derechos humanos y la falta de liderazgo regional en derechos humanos; los retos diversos asociados al carácter dispar y disputado de los procesos regionales de democratización; y la fragilidad de los mecanismos regionales -con tensiones institucionales atravesadas- para promover y proteger los derechos humanos y la democracia.

\section{Retos continuos de los derechos humanos y falta de liderazgo estatal}

A pesar de los adelantos importantes en las décadas recientes, en buena medida el Sistema Interamericano aún enfrenta desafíos considerables de derechos humanos. La proliferación de gobiernos electos en América Latina apunta hacia una mejora en general de la situación de los derechos humanos, aunque aún llegan casos de serias e indisputables violaciones a la Comisión Americana. No sólo se reciben casos en la Comisión desde la "frontera gris donde la autoridad del Estado para fomentar el interés general choca con los derechos individuales", ${ }^{80}$ sino que violaciones sostenidas y "estructurales" siguen ocurriendo a gran escala, como brutalidad policiaca, asesinato de niños de la calle, violencia rural y discriminación continua de las personas indígenas. Así, el rumbo generalizado de los derechos humanos podría caracterizarse como un distanciamiento de las violaciones "tradicionales" perpetradas por agentes estatales como parte de una política estatal deliberada. Las causas de las violaciones estructurales de derechos humanos no residen en el ejercicio arbitrario del poder sino que son consecuencias de las debilidades de los Estados y de los fracasos en el desempeño. En muchos casos, el papel de las autoridades estatales podría ser difícil de demostrar, o estar del todo ausente, y la capacidad de las instituciones estatales débiles e ineficientes para atender tales violaciones podría estar extremadamente limitado.

${ }^{80}$ Farer, "Rise of the Inter-American Human Rights Regime", p. 544. 
Esta tendencia plantea cambios mayores para el sistema regional de derechos humanos, que está dirigido a la protección de los individuos contra las acciones del Estado y que está construido en torno a nociones legales de responsabilidad estatal, y que asume, políticamente, que se puede ejercer presión en los Estados con la influencia para mejorar la situación. En otras palabras, los Estados que son parte del problema también pueden ser parte de la solución.

De hecho, el sistema regional de derechos humanos sigue inmerso en el sistema regional de Estados a la vez que depende fuertemente del liderazgo estatal para provocar cambios. En el sentido tradicional de los derechos humanos, éstos habrán de disfrutarse en sociedades nacionales como derechos protegidos por la ley nacional. La intención del derecho internacional, desde esta perspectiva, es influir en los Estados para que reconozcan y acepten los derechos humanos, para reflejar estos derechos en sus constituciones nacionales y leyes, y para respetar y asegurar su goce con instituciones nacionales e incorporarlos al modo de vida nacional. ${ }^{81}$ Esta perspectiva sobre el devenir político del SIDH considera los derechos humanos íntimamente ceñidos al poder estatal. Para unos, los derechos humanos sólo "importan" cuando los Estados poderosos los establecen y buscan emplear su propio poder para cumplir los estándares de derechos humanos. Para otros, el régimen de derechos humanos puede importar, pero en principio por lo que puede hacer para mover incentivos ante los Estados miembros, generando publicidad, señalando y acusando, creando nexos positivos y negativos con otros temas.

Con todo, como se explicó en la sección anterior, Estados Unidos ha tenido, en el mejor de los casos, un liderazgo ambiguo en el desarrollo del sidh. Por una parte, Estados Unidos ocasionalmente ha canalizado su poder a través del SIDH para aparentar un cambio en los derechos humanos; más aún, el mismo país es todavía la fuente para financiar al sidH. Aún así, el liderazgo de su gobierno sobre derechos humanos, cuando se ha intentado, sigue cargado

${ }^{81}$ Louis Henkin, "International Human Rights and Rights in the United States", en Theodor Meron (ed.), Human Rights in International Law: Legal and Policy Issues, Oxford, Oxford University Press, 1989, p. 25. 
de conflicto. Son añejas y perdurables las "señales encontradas" de la institución política estadounidense ante los derechos humanos en la región tanto como en ultramar. ${ }^{82}$ Los cambios en el clima securitario más amplio durante la última década han tenido "claramente repercusiones negativas para los derechos humanos, en términos de las violaciones a los derechos humanos que el propio Estados Unidos cometió, notablemente en Guantánamo, en términos del cinismo que lo dispar entre las palabras y los actos de Estados Unidos ha ocasionado en la región, en términos de los incentivos y espacios políticos para que otros grupos emulen la retórica y comportamiento de Washington". ${ }^{83}$ Más aún, el ambiente donde se anteponía la seguridad resulta cada vez más institucionalizado. Hubo muchos comentaristas que interpretaron la alta retórica del candidato presidencial Barack Obama de restaurar la autoridad moral de Estados Unidos como un compromiso inequívoco y renovado sobre los lineamientos de los derechos humanos. Como sea, aun más allá de la promesa fallida de cerrar el campo de detención de la Bahía de Guantánamo, la administración de Obama ha mantenido el curso de la "guerra contra el terrorismo", con, por ejemplo, el uso creciente de las muertes extrajudiciales con drones no tripulados. En América Latina, la administración de Obama siguió apoyando una militarización en aumento que responde a la violencia en México relacionada con el tráfico de drogas con sus implicaciones predecibles sobre derechos humanos. Ante la ausencia de un liderazgo moral de Estados Unidos en la región, los defensores de los derechos humanos y los funcionarios del sidH se han vuelto hacia los Estados influyentes de América Latina en busca de liderazgo. Como quiera que sea, según veremos, más allá de algunas excepciones notables, los Estados influyentes latinoamericanos se disputan cada vez más el sIDH, con frecuencia bajo la suposición de que el SIDH no es otra cosa que un frente para los intereses de Estados Unidos.

${ }^{82}$ Kathryn Sikkink, Mixed Signals: U.S. Human Rights Policy and Latin America, Ithaca, Cornell University Press, 2004.

83 Par Engstrom y Andrew Hurrell, "Why the Human Rights Regime in the Americas Matters", en Mónica Serrano y Vesselin Popovski (eds.), Human Rights Regimes in the Americas, Tokio, United Nations University Press, 2010. 


\section{Desafios de la democratización}

La democracia, como régimen político, puede quedar como "la única alternativa" en las Américas. Con todo, los retos contemporáneos para la democracia en América Latina tienen menos que ver con la amenaza de golpes militares y el fracaso de mantener elecciones limpias, que con la lenta erosión de los sistemas democráticos. Mientras que el acto de detentar el poder es más bien ambiguo, hay múltiples vías por las que el poder logrado por medios democráticos puede ejercerse de formas nada democráticas. ${ }^{84}$ En efecto, las democracias de la región que de hecho existen están débilmente institucionalizadas y los derechos ciudadanos resultan con ello inestables. Las diferencias entre las características formales y procesales de los acuerdos políticos y las percepciones subjetivas de las experiencias con la democracia de quienes viven bajo su régimen varían entre países y en ellos mismos. ${ }^{85}$ En el mismo sentido, el principal desafío para el orden democrático en la región no es la vuelta al autoritarismo, sino las "fracturas" de los regímenes democráticamente electos. ${ }^{86}$ De esta manera, partiendo de la concepción procesal y minimalista de la democracia, ${ }^{87}$ según implica en paradigma de la consolidación, las expectativas de lo que la democracia debiera rendir, y cómo, se expanden. Conforme cambian las exigencias de la democracia, la realidad no necesariamente las sigue. En particular, es ancha y puede ir en aumento la brecha entre las aseveraciones y predicciones del paradigma de consolidación y las experiencias subjetivas de la democracia en la

${ }^{84}$ Sobre declaraciones sobre democracias no-liberales, véase Fareed Zakaria, The Future of Freedom: Illiberal Democracy at Home and Abroad, Nueva York, W.W. Norton \& Co., 2003. Para una discusión sobre la democracia liberal en América Latina, véase Laurence Whitehead, “The Alternatives to 'Liberal Democracy': A Latin American Perspective”, en David Held (ed.), Prospects for Democracy: North, South, East, West, Cambridge, Polity Press, 1993.

${ }^{85}$ O'Donnell, "On the State, Democratization, and Some Conceptual Problems".

${ }^{86}$ Felipe Agüero y Jeffrey Stark, Fault Lines of Democracy in Post-Transition Latin America, Coral Gables, Florida, North-South Center Press/University of Miami, 1998.

${ }^{87}$ Linz y Stepan, "Toward Consolidated Democracies". 
región. Hay, en otras palabras, diferencias significativas en términos de resultados políticos de la democratización a lo largo de la región, las cuales cuestionan una narrativa inequívoca de la convergencia regional en torno a valores de democracia liberal.

Dichas diferencias tienen consecuencias de largo alcance para el SIDH. En particular, las interpretaciones normativas del sentido del orden democrático han variado especialmente durante la última década. Mientras que Estados Unidos se mantiene abiertamente crítico ante los gobiernos orientados hacia la izquierda en la región y ante lo que entiende como abusos de mandatarios "populistas", "ha habido un descontento generalizado a lo largo de la región con los resultados de la democracia y la reforma económica liberal; se suceden los llamados a una mucho mayor atención a la agenda social y se proclaman modos más "auténticos", "redistributivos" y "participativos" de la democracia (notablemente en Venezuela y Bolivia)" ${ }^{88}$ Los conflictos recientes sobre las críticas de la Comisión Interamericana de la erosión de la libertad de expresión y de la independencia del poder judicial en Ecuador, y en particular en Venezuela, indican que el sIDH está preso en la vorágine diplomática de acusaciones y contraacusaciones. Como hemos argumentado con Andrew Hurrel en otra parte, "cualquiera que sea la verdad exacta de estas afirmaciones respectivas (en que ambos lados presentan una imagen asaz simplista del cambio político en la región), el punto aquí es simplemente notar la dificultad del siDH en sus esfuerzos para promover y proteger los derechos humanos y la democracia cuando hay tan poco consenso sobre el significado de la democracia y la dirección al que debería encaminarse el cambio democrático". ${ }^{89}$

\section{Tensiones dentro de las instituciones regionales y entre ellas}

Los numerosos desafíos a los derechos humanos y a la democracia en la región en efecto se superponen. Con todo, existe poco apoyo

${ }^{88}$ Par Engstrom y Andrew Hurrell, "Why the Human Rights Regime in the Americas Matters”, en Mónica Serrano y Vesselin Popovski (eds.), op. cit., p. 50.

${ }^{89}$ Loc. cit. 
mutuo entre el Sistema Interamericano de Derechos Humanos y otros mecanismos regionales, incluida la Carta Democrática Interamericana. ${ }^{90}$ Aunque el derecho de un pueblo a la democracia se afirma en la Carta Democrática, donde la protección de los derechos humanos se considera esencial, por encima y más allá de la celebración de elecciones periódicas los mecanismos para evaluar e implementar de la Carta son poco claros. ${ }^{91}$ Además, en términos de la Carta, la oeA actuará al final según su propia discreción al elegir si interviene (o no) en la defensa de los principios democráticos. ${ }^{92}$ Esto coloca al Estado en cuestión en la posición de elegir si solicita investigar, dejando a los grupos de la sociedad civil buscar que se active una investigación por supuestas infracciones a la Carta Democrática sin un recurso provisto para ello en la misma. ${ }^{93}$

Por consiguiente, los Estados regionales han construido un régimen regional con el fin de proteger y promover la democracia, el cual está bajo el control directo de los Estados. En comparación con el sidH, es menos limitante, y menos susceptible de desarrollo progresivo tanto dentro del sistema como por los grupos de la

${ }^{90}$ Como notaron Cooper y Thérien, la "promoción de la democracia ayudaría a hacer cumplir los derechos humanos y, por el contrario, la promoción de los derechos humanos podría apoyar el desarrollo de un orden democrático". Aún así, al día de hoy, en la práctica "los derechos humanos y la democracia aparecen por lo común desligados en la agenda interamericana". Cooper y Thérien, "InterAmerican Regime of Citizenship”, p. 732.

${ }^{91}$ La Carta es vaga en particular al definir las condiciones que constituirían una violación: "la alteración anticonstitucional o la interrupción del orden democrático como queda inscrito en el artículo 19".

${ }^{92}$ El mecanismo descrito en el artículo 17 de la Carta Democrática -"Cuando el gobierno de un Estado Miembro considere que está en riesgo su proceso político institucional democrático o su legítimo ejercicio del poder"- sugiere que los Estados miembros deben pedir la intervención de la oEA, al menos en primera instancia.

${ }^{93}$ En caso de una "interrupción” más dramática del orden constitucional, como un golpe de Estado, cualquier Estado miembro puede solicitar que se inicie un proceso de asesoría, cuyas consecuencias podrían incluir la suspensión de la oEA del Estado miembro infractor. Con todo, el mecanismo para la acción colectiva es débil porque aún no queda claro si la aquiescencia del Estado en cuestión es una condición previa dicha acción. Estas tensiones quedaron claramente ilustradas después del golpe militar en Honduras en junio y julio de 2009. 
sociedad civil. Dados estos sesgos basados en el Estado, inherentes al régimen democrático, las consideraciones políticas influyen inevitablemente el objetivo declarado de defender la democracia. Más aún, no hay referencia explícita al Sistema Interamericano de Derechos Humanos en la Carta Democrática. Mientras que el sistema de derechos humanos ha buscado cada vez más conectar la protección de los derechos humanos y la forma democrática de gobierno, aún son distintos los mecanismos institucionales desarrollados para tratar estos desafíos superpuestos. La Comisión Interamericana de Derechos Humanos podría jugar un papel importante en comenzar el debate en torno a las situaciones que parecen amenazar la gobernanza democrática, al ayudar a presentar "advertencias tempranas" sobre los quiebres en la democracia, al estudiar las situaciones que ameriten tomar medidas bajo la Carta Democrática y al evaluar la aplicación de dichas medidas.

Esto requeriría, con todo, estructuras institucionales de cooperación hemisférica mucho más robustas de las que ya existen; también, un grado de convergencia entre las relaciones de Estados Unidos y América Latina alrededor de preferencias compartidas y lineamientos normativos de democracia y derechos humanos. Si la década de 1990 se caracterizó por el optimismo ante los derechos humanos y la democracia en las Américas, lo que reflejaba una percepción generalizada de preferencias liberales compartidas y valores, la década de 2000 se definió por un retorno a las preocupaciones sobre el poder, los conflictos ideológicos y las controversias por los alegatos de soberanía y hegemonía estadounidense. $\mathrm{Si}$ el término de la presidencia de Bush trajo esperanzas en algunos espacios de un cambio de curso en las políticas de Estados Unidos en la región, las continuidades de políticas de la administración de Obama son sin duda significativas (como se ve en la continua militarización de México con la Iniciativa Mérida o en la aceptación final de Estados Unidos del gobierno de Honduras después del golpe). En el proceso, las ambiciosas iniciativas institucionales de los años noventa, incluidas las Cumbres de las Américas y la propuesta del Área de Libre Comercio de las Américas (ALCA), se han politizado en exceso o se abandonaron. La oEA también se ha ido guardando de atender los muchos retos de los derechos humanos, 
la inseguridad, la inequidad, el orden democrático y el desarrollo económico en la región. Y mientras que prosiguió con Obama el declive de la importancia de América Latina para la política exterior estadounidense, el centro de gravedad del panorama institucional se ha desplazado de Washington hacia acuerdos competitivos regionales, como la Unasur (Unión de Naciones Suramericanas), que buscan explícitamente excluir a Estados Unidos. Muchos países latinoamericanos buscan cada vez más más allá de la región en busca de cooperación diplomática y económica (China, la India, Turquía e Irán).

El SIDH está en un punto claramente delicado por estas vías divergentes de institucionalización regional. En particular la Comisión Interamericana enfrenta duras críticas de varios países influyentes en la región, incluido Venezuela, que, bajo el gobierno del entonces presidente Hugo Chávez, eligió renunciar a la jurisdicción de la Corte Interamericana. En el caso de Brasil, la respuesta del gobierno de Dilma Roussef fue muy pronta a la adopción de alto perfil de una medida provisional de la CIDH en abril de 2011, que solicitaba a Brasil detener la construcción de la presa de Belo Monte. La presidenta Roussef decidió suspender la contribución anual de Brasil a la CIDH, llamar temporalmente a su embajador en la oeA y retirar la candidatura de su antiguo ministro para los Derechos Humanos, Paulo Vannuchi, para ser miembro de la Comisión Interamericana. Aunque el gobierno brasileño ha emprendido un regreso gradual al statu quo, según se vio en la elección reciente de Vannuchi en la Comisión, fue dañino el desafío directo y público para la autoridad de la CIDH de parte de un país ampliamente considerado crucial dentro y fuera del sidH para el futuro de la gobernanza regional.

De hecho, la aparición de organizaciones subregionales en América Latina, desafiante para la oeA, ha adquirido cierto impulso. Antes del fallecimiento de Hugo Chávez, hubo consideraciones concretas para la creación de órganos de derechos humanos como parte de la Unasur o la Comunidad de Estados Latinoamericanos y Caribeños (CELAC). Más aún, con la consolidación del régimen de derechos humanos del Mercosur, el sidH puede parecer menos y menos "la única alternativa" para los 
muchos grupos e individuos que buscan una reparación internacional a los abusos de derechos humanos en América Latina. De aquí que, como se vio en el proceso reciente de reforma del SiDH, algunos países latinoamericanos son enérgicos en sus esfuerzos para cambiar las reglas institucionales del juego regional. Sus críticas a la oEA, asociadas por lo común al sIDH, se sugieren en términos de condenaciones del dominio percibido de Estados Unidos sobre estas instituciones. Ciertamente, Estados Unidos aporta aún la mayor parte de los fondos para el sidH, y desde luego financiar siempre acarrea algunos compromisos. Aún así, es igualmente cierto que el sidH figure muy abajo en la agenda exterior estadounidense, incluso en sus relaciones con América Latina. En efecto, el aspecto sorprendente es la combinación de indiferencia con que ciertos gobiernos de la oEA, en particular el de Estados Unidos, tratan al sidH, como se evidenció en índices desiguales de ratificación (Estados Unidos, Canadá, el Caribe anglófono, que no ratificaron la Convención Americana ni aceptaron la jurisdicción de la Corte Interamericana), en la falta de apoyo financiero adecuado y en los índices irregulares de cumplimiento.

\section{Conclusión}

El Sistema Interamericano de Derechos Humanos se ha ganado un sitio central con los años en el paisaje institucional regional de las Américas. Claramente, el carácter de las relaciones entre Estados Unidos y América Latina ha determinado el desarrollo del sIDH, y, como este artículo ha buscado ilustrar, el SIDH, a su vez, ha tenido un impacto no desdeñable en la política del hemisferio. De hecho, el desarrollo institucional del SIDH requiere entenderse en términos de un contexto histórico y geopolítico de las relaciones entre Estados Unidos y América Latina más amplio, lo que continúa definiendo el funcionamiento del sistema, como se demostró ampliamente en el contexto del proceso de reforma del sidH en años recientes. Aun así, un enfoque exclusivo de la política interestatal del Sistema Interamericano se arriesgaría a descuidar las vías por 
las cuales el SIDH es relevante para los ciudadanos y grupos a lo largo de la región. El sidH se ha alejado de manera significativa de sus orígenes institucionales como un régimen intergubernamental "clásico". Una corte independiente regional de derechos humanos y una comisión autónoma juzgan regularmente si los Estados regionales están de acuerdo con sus obligaciones internacionales sobre derechos humanos. El acceso de individuos y organizaciones regionales de derechos humanos al régimen de derechos humanos se ha fortalecido con el tiempo. Aunque persisten diferencias claras entre los países de la región, la evolución normativa e institucional del SIDH ha llevado a una creciente interacción entre los procesos internos políticos, los órdenes legales nacionales y las instituciones regionales de derechos humanos. En el proceso, el SIDH ha quedado inscrito en sistemas políticos y legales internos y se lo usa cada vez más para la implementación de normas regionales de derechos humanos. Estos procesos de regionalización han abierto espacio para la agencia política transnacional, ofreciendo oportunidades para que los actores de derechos humanos internos y transnacionales induzcan un cambio en sus sistemas internos políticos y jurídicos.

Sin duda, es importante reconocer las verdaderas limitaciones del SIDH y mantenerse claros sobre los muchos retos del sistema. E incluso así, sigue habiendo razones para mantenerse optimista, con cautela, sobre el futuro del sidH. El sistema realiza un trabajo valioso por debajo del radar de la diplomacia regional interestatal. Más aún, aunque el proceso de reforma estuvo dominado sobre todo por gobiernos que intentaban maniatar al sIDH, en particular, y reducir su autonomía, la movilización de una red regional de grupos de derechos humanos en apoyo del sidH resultó relativamente efectiva. Aún más decisiva, como se reflejó en las peticiones en aumento firme al SIDH, la demanda de las víctimas y sus familiares, y de las organizaciones de derechos humanos a lo largo de la región, sigue robusta y creciendo.

Traducción de Gabriel Ramos 


\section{BibliogRAFía}

Agüero, Felipe y Jeffrey Stark, Fault Lines of Democracy in Post-Transition Latin America, Coral Gables, Florida, North-South Center Press/University of Miami, 1998.

Brysk, Alison, Globalization and Human Rights, Berkeley, University of California Press, 2002.

Brysk, Alison y Gershon Shafir, People Out of Place: Globalization, Human Rights and the Citizenship Gap, Londres, Routledge, 2004.

Buergenthal, Thomas y Dinah Shelton, Protecting Human Rights in the Americas: Cases and Materials, Estrasburgo, International Institute of $\mathrm{Hu}-$ man Rights, 1995.

Carozza, Paolo G., "From Conquest to Constitutions: Retrieving a Latin American Tradition of the Idea of Human Rights", Human Rights Quarterly, vol. 25, núm. 2, 2003, pp. 281-313.

Cassel, Douglass, "A United States View of the Inter-American Court of Human Rights", en Antonio A. Cançado Trindade (ed.), The Modern World of Human Rights, San José, Inter-American Institute of Human Rights, 1996.

Cooper, Andrew F., "The Making of the Inter-American Democratic Charter: A Case of Complex Multilateralism”, International Studies Perspectives, vol. 5, núm. 1, 2004, pp. 92-113.

Cooper, Andrew F. y Thomas Legler, "The oAs Democratic Solidarity Paradigm: Questions of Collective and National Leadership”, Latin American Politics and Society, vol. 43, núm. 1, 2001, pp. 103-126.

Cooper, Andrew F. y Thomas Legler, "A Tale of Two Mesas: The oAs Defense of Democracy in Peru and Venezuela”, Global Governance, vol. 11, núm. 4, 2005, pp. 425-444.

Cooper, Andrew F. y Thomas F. Legler, Intervention without Intervening? The oAs Defense and Promotion of Democracy in the Americas, Basingstoke, Palgrave Macmillan, 2006.

Cooper, Andrew F. y Jean-Philippe Thérien, “The Inter-American Regime of Citizenship: Bridging the Institutional Gap between Democracy and Human Rights”, Third World Quarterly, vol. 25, núm. 4, 2004, pp. 731-746.

Cooper, Andrew F., "The Quebec City 'Democracy Summit'”, Washington Quarterly, vol. 24, núm. 2, 2001, pp. 159-171. 
Donnelly, Jack, Universal Human Rights in Theory and Practice, Ithaca, Cornell University Press, 1989.

Due Process of Law Foundation, Victims Unsilenced: The Inter-American Human Rights System and Transitional Justice in Latin America, Washington, D. C., Due Process of Law Foundation, 2007.

Engstrom, Par, "Transnational Human Rights and Democratization: Argentina and the Inter-American Human Rights System (1976-2007)", tesis doctoral, University of Oxford, 2010, caps. 1-2.

Engstrom, Par y Andrew Hurrell, "Why the Human Rights Regime in the Americas Matters", en Mónica Serrano y Vesselin Popovski (eds.), Human Rights Regimes in the Americas, Tokio, United Nations University Press, 2010.

Farer, Tom (ed.), Beyond Sovereignty: Collectively Defending Democracy in the Americas, Baltimore, The Johns Hopkins University Press, 1996.

—, "The Rise of the Inter-American Human Rights Regime: No Longer a Unicorn, Not Yet an Ox", Human Rights Quarterly, vol. 19, núm. 3, 1997, pp. 526-527.

Fawcett, Louise, "The Origins and Development of Regional Ideas in the Americas", en Louise Fawcett y Mónica Serrano (eds.), Regionalism and Governance in the Americas: Continental Drift, Basingstoke, Palgrave Macmillan, 2005.

Forsythe, David, "Human Rights, The United States and the Organization of American States", Human Rights Quarterly, vol. 13, pp. 66-98.

Franck, Thomas, "The Emerging Right to Democratic Governance", The American Journal of International Law, vol. 86, núm. 1, pp. 46-91. , "Democracy as a Human Right", Studies in Transnational Legal Policy, 26, 1994.

—, "The Democratic Entitlement", University of Richmond Law Review, vol. 29, núm. 1, 1994.

García Bauer, Carlos, "The Observance of Human Rights and the Structure for Their Protection in the Western Hemisphere", American University Law Review, vol. 30, núm. 14, 1980-1981.

Glendon, Mary Ann, "The Forgotten Crucible: The Latin American Influence on the Universal Rights Idea", Harvard Human Rights Journal, vol. 16, 2003.

Gómez, Verónica, "The Interaction between the Political Actors of the OAs, the Commission and the Court", en David J. Harris y Stephen 
Livingstone (eds.), The Inter-American System of Human Rights, Oxford, Clarendon Press, 1998.

Harris, David, "Regional Protection of Human Rights: The Inter-American Achievement", en David Harris and Stephen Livingstone (eds.), The Inter-American Human Rights System, Oxford, Clarendon Press, 1998.

Hurrell, Andrew, "Security in Latin America", International Affairs, vol. 74, núm. 3, 1998.

, "Hegemony and Regional Governance in the Americas", en Louise Fawcett y Mónica Serrano (eds.), Regionalism and Governance in the Americas: Continental Drift, Basingstoke, Palgrave Macmillan, 2005.

Henkin, Louis, "International Human Rights and Rights in the United States”, en Theodor Meron (ed.), Human Rights in International Law: Legal and Policy Issues, Oxford, Oxford University Press, 1989.

IACHR Reports 20/78, 21/78, 22/78 y 27/78 (Argentina), y IACHR's Annual Report 1979-1980.

Ignatieff Michael (ed.), American Exceptionalism and Human Rights, Princeton University Press, 2005.

Korzeniewicz, Roberto Patricio y William C. Smith, "Transnational Civil Society Actors and Regional Governance in the Americas: Elite Projects and Collective Action from Below", en Fawcett y Serrano, op. cit.

Lutz, Ellen L. y Kathryn Sikkink, "International Human Rights Law and Practice in Latin America”, International Organization, vol. 54, núm. 3, 2000, pp. 633-659.

Medina, Cecilia, "Inter-American Commission on Human Rights and the Inter-American Court of Human Rights: Reflections on a Joint Venture”, Human Rights Quarterly, vol. 12, núm. 4, 1990, pp. 439-464.

Muñoz, Heraldo, "The Right to Democracy in the Americas", Journal of Interamerican Studies and World Affairs, vol. 40, núm. 1, 1998, pp. 1-18.

O'Donnell, Guillermo A., Modernization and Bureaucratic-Authoritarianism: Studies in South American Politics, Berkeley, Institute of International Studies, University of California Press, 1973.

Padilla, David J., "The Inter-American System for the Promotion and Protection of Human Rights", Georgia Journal of International and Comparative Law, vol. 20, núm. 2, 1990, pp. 395-405.

Panizza, Francisco, "Human Rights: Global Culture and Social Fragmentation”, Bulletin of Latin American Research, vol. 12, núm. 2, 1993. 
Pasqualucci, Jo M., "Preliminary Objections before the Inter-American Court of Human Rights: Legitimate Issues and Illegitimate Tactics", Virginia Journal of International Law, vol. 40, núm. 1, 1999, pp. 1-114.

Pastor, Robert A., Exiting the Whirlpool: U.S. Foreign Policy Toward Latin America and the Caribbean, Boulder, Westview, 2001.

Peddicord, Jane D., "The American Convention on Human Rights: Potential Defect and Remedies", Texas International Law Journal, vol. 19, núm. 1, 1984, pp. 139-159.

Schoultz, Lars, Human Rights and United States Policy toward Latin America Princeton, Princeton University Press, 1981.

Sikkink, Kathryn, "The Emergence, Evolution, and Effectiveness of the Latin American Human Rights Network", en Elizabeth Jelin y Eric Hershberg (eds.), Constructing Democracy: Human Rights, Citizenship and Society in Latin America, Boulder, Westview, 1997, pp. 59-84.

— Mixed Signals: U.S. Human Rights Policy and Latin America, Ithaca, Cornell University Press, 2004.

—, "Reconceptualizing Sovereignty in the Americas: Historical Precursors and Current Practices”, Houston Journal of International Law, vol. 19, 1996-1997.

Weissbrodt, David y María Luisa Bartolomei, "The Effectiveness of International Human Rights Pressures: The Case of Argentina, 19761983", Minnesota Law Review, vol. 75, núm. 3, febrero de 1991, pp. 1009-1035.

Whitehead, Laurence, "The Alternatives to 'Liberal Democracy': A Latin American Perspective", en David Held (ed.), Prospects for Democracy: North, South, East, West, Cambridge, Polity Press, 1993.

Zakaria, Fareed, The Future of Freedom: Illiberal Democracy at Home and Abroad, Nueva York, W.W. Norton \& Co., 2003. 